\title{
Shape Control of Metal Halide Perovskite Single Crystals: From Bulk to
}

\section{Nanoscale}

Anbo Feng, ${ }^{\dagger \#}$ Xiaomei Jiang, ${ }^{\dagger \#}$ Xiaoyu Zhang, ${ }^{* £}$ Xiaopeng Zheng, ${ }^{\ddagger}$ Weitao Zheng,,

Omar F. Mohammed, ${ }^{\dagger}$ Zhaolai Chen, ${ }^{* \dagger}$ Osman M. Bakr*

${ }^{\dagger}$ State Key Laboratory of Crystal Materials, and Institute of Crystal Materials, Shandong University, No. 27 Shanda South Road, Jinan, 250100 (P.R. China)

${ }^{£}$ Key Laboratory of Automobile Materials of Ministry of Education, and College of Materials Science, Jilin University, Changchun 130012, China.

\#Division of Physical Sciences and Engineering, King Abdullah University of Science and Technology (KAUST), Thuwal 23955-6900, Saudi Arabia

*E-mail: $\quad$ zhangxiaoyu @jlu.edu.cn; $\quad$ zhaolaichen @ sdu.edu.cn; osman.bakr@kaust.edu.sa

\begin{abstract}
Metal halide perovskite (MHP) single crystals are promising candidates for photovoltaics and related optoelectronic devices. They afford optical and charge transport properties superior to those of their polycrystalline counterparts. Despite this advantage, MHP single crystals are less widely adopted. Traditional bulk growth methods do not lend single-crystal MHPs to device integration as readily as their polycrystalline analogues, which are amenable to a multitude of approaches for deposition and growth. Fortunately, diverse shape-control approaches for MHP single crystals have been recently reported, enabling tunable optoelectronic properties and expanding the potential for single-crystal applications. In this review, we summarize
\end{abstract}


recent developments in the shape control of MHP single crystals, including those pertaining to microcrystals, single-crystal thin films, nano-/microplates, nano/microrods, and nanocrystals. We highlight strategies for optimizing the synthesis of these crystals to achieve targeted materials properties and device performance. This review aims to guide the future of shape design in MHP single crystals for various optoelectronic applications.

\section{Introduction}

Metal halide perovskites (MHPs) are a class of materials with the formula $\mathrm{ABX}_{3}$, where $\mathrm{A}$ is a monovalent cation, $\mathrm{B}$ is a divalent metal ion such as $\mathrm{Pb}^{2+}$ or $\mathrm{Sn}^{2+}$, and $\mathrm{X}$ is a halide anion. For organic-inorganic hybrid perovskites, A is usually methylammonium $\left(\mathrm{MA}^{+}\right)$or formamidinium $\left(\mathrm{FA}^{+}\right)$, whereas for all-inorganic perovskites, A is typically $\mathrm{Cs}^{+}$. Recently, the outstanding optical and electrical properties of MHPs have been disclosed; these include a high absorption coefficient ${ }^{1}$, unique defect physics, a long charge carrier recombination lifetime ${ }^{2}$, a long charge carrier diffusion length ${ }^{3}$, and high charge carrier mobility ${ }^{4}, 5$, which make MHPs promising candidates for optoelectronic applications. The efficiency of perovskite solar cells has rocketed from $3.8 \%$ to $25.2 \%$ after only ten years of development ${ }^{6-14}$, demonstrating great potential for commercial utilization. In addition to photovoltaics, MHP materials are also widely investigated for use in photodetectors ${ }^{15-23}$, X-ray imaging $^{24-29}$, lasers ${ }^{30-34}$, and light-emitting diodes (LEDs). ${ }^{35-38}$

The intrinsic optoelectronic properties of MHP single crystals were first investigated in 2015. ${ }^{3,}{ }^{39}$ Since then, it has been found that MHP single crystals exhibit better 
properties than those of polycrystalline thin films due to the absence of grain boundaries. ${ }^{40-47}$ For example, the trap state density of MHP single crystals was reported to be in the range of $10^{9}-10^{11} \mathrm{~cm}^{-3}$, approximately five orders of magnitude lower than that of MHP polycrystalline thin films. ${ }^{42,}, 48,49$ This ultra-low trap density led to ultralong charge carrier diffusion lengths of several tens to hundreds of micrometers. ${ }^{50,51}$ Additionally, MHP single crystals also showed enhanced moisture, thermal, and light stability compared with polycrystalline thin films. ${ }^{52-54}$ Therefore, it is universally recognized that perovskite single crystals are appealing for the development of highperformance and more stable optoelectronic devices.

In the early days of single-crystal MHP research, millimeter- or centimeter-sized bulk single crystals were mainly investigated, and they were discovered to be excellent high-energy radiation and visible-light detectors. ${ }^{16,}$ 24, 46, 55-57 However, bulk single crystals usually present poor emission properties, and their large thickness causes ineffective carrier transport across whole crystals, hindering their application in other types of optoelectronic devices, such as solar cells, LEDs, and lasers. Fortunately, diverse single crystal shapes offer a flexible platform for constructing highperformance devices for specific applications. For instance, by reducing the thickness of a bulk single crystal to that of a single crystal thin film, enhanced photophysical and electrical properties could be achieved (relative to those of polycrystalline thin films) specifically, improved carrier generation and transport efficiencies as well as a broader light absorption spectrum; thus, the single-crystal thin film represents the most promising geometry for applications in solar cells, photodetectors, and other 
optoelectronic devices. Meanwhile, MHPs with low-dimensional shapes, such as twodimensional (2D) platelets and one-dimensional (1D) rods, possess optical and electrical properties that are absent in their bulk counterparts as a result of quantum confinement and steric anisotropy effects. ${ }^{29,58-62}$ Specifically, in micro-/nanoplates, electrons and holes are strongly confined in two dimensions, rendering a large exciton binding energy and high luminescence yield and thus demonstrating great promise for light-emitting applications. ${ }^{63,64}$ Additionally, high-quality lasing action has been realized in 2D microplates, which act as naturally formed single-crystalline whisperinggallery-mode microcavities. ${ }^{33}$ Moreover, $1 \mathrm{D}$ rods and wires that possess a high lengthto-width ratio and a well-defined size and morphology are perfect for lasing applications due to the efficient transport and propagation of charge carriers and photons along the longitudinal direction. ${ }^{65,}{ }^{66}$ Further reducing the dimensionality of single crystals to zero yields nanocrystals, which measure several to hundreds of nanometers and are highly desirable in light-emitting applications for their characteristic properties, including near-unity quantum yield, high color purity, and size- or surface-chemistry-dependent emission spectra. ${ }^{67-72}$ The aforementioned examples clearly indicate that developing shape-controlled MHP single crystals and realizing the full potential of their unique shape-dependent properties has broad implications for the major classes of optoelectronic applications.

To date, great progress has been achieved in exploring methods for growing single crystals with different shapes. ${ }^{58,73-76}$ Nevertheless, major challenges remain in achieving single-crystal-based high-performance device applications. For example, 
there is an urgent need for effective methods for growing thickness-controllable singlecrystal thin films with a large area and of high quality. Furthermore, for nanocrystals, the nucleation and growth steps are fast and hardly separable in time, which imposes difficulties on the synthesis of target nanocrystals with controlled size and high ensemble uniformity. Additionally, systematic knowledge about how ligands affect nucleation, growth, and shape evolution currently remains insufficient.

In this review, we focus on recent developments in the shape control of MHP single crystals, including microcrystals, single crystal thin films, micro-/nanoplates, micro/nanorods, and nanocrystals. We highlight strategies for optimizing the synthesis of these crystals to achieve better materials properties and device performance. This review aims to provide guidelines for the future design of MHP single crystals and for promoting their optoelectronic applications.

\section{Crystal nucleation and growth}

Diverse single-crystal shapes can be achieved by effectively managing the thermodynamics and kinetics of nucleation and growth. According to classical nucleation theory ${ }^{77}$, the nucleation of a single crystal is initiated by overcoming the Gibbs free energy $\left(\Delta \mathrm{G}_{\mathrm{T}}\right)$, which includes a negative bulk volume term $\left(\mathrm{G}_{\mathrm{v}}\right)$ proportional to $\mathrm{r}^{3}$ and a positive surface-tension-related term $\left(\mathrm{G}_{\mathrm{s}}\right)$ proportional to $\mathrm{r}^{2}$ :

$$
\Delta G_{T}=\Delta G_{v}+\Delta G_{S}=-\frac{4}{3} \pi \frac{r^{3}}{V} \Delta \mu+4 \pi r^{2} \sigma
$$

where $r, V, \Delta \mu$, and $\sigma$ represent the radius of the nucleus, the volume of each molecule, the difference in the free energy of the system between its final and initial states, and the surface free energy, respectively. $\Delta \mu$ can also be thermodynamically expressed as 
follows:

$$
\Delta \mu=k T \ln S
$$

where $k, T$, and $S$ refer to the Boltzmann constant, absolute temperature, and supersaturation ratio, respectively. For solution-based growth methods, supersaturation can be initiated by regulating temperature, by adjusting the evaporating solvents, or by introducing poor solvents into the solution. ${ }^{39,40,78}$ Factors such as temperature, solvent, concentration, pressure, and wettability/hydrophobicity play crucial roles in controlling the growth and final shape of the crystals. ${ }^{79,80}$ For example, Jin et al. obtained $\mathrm{MAPbI}_{3}$ single crystals in the forms of nanowires, nanorods, and nanoplates by controlling the concentration of MAI. ${ }^{76}$ Notably, surface energy is one of the most significant parameters affecting the nucleation process, and manipulating surface structures can affect further growth. Nucleation is more likely to occur at the water-air interface than in the bulk solution. Therefore, to obtain a single-crystal film with a large aspect ratio, strategies have been designed such that crystal growth occurs at the solution-air interface or in a geometrically confined space between two substrates. ${ }^{1,50,81}$ According to thermodynamics, high-energy surfaces favor a faster growth rate than low-energy surfaces do. Due to the effects of surface-bound ligands on growth kinetics, crystals can be directed to form low-dimensional nanostructures with high anisotropy, such as 1D wires/rods and 2D plates. By varying the main preparation parameters - such as reaction time, injection and growth temperatures, and injection time- the aspect ratio, size, and growth rate of these structures can be systematically controlled. ${ }^{34,82,83}$

\section{Microcrystals}



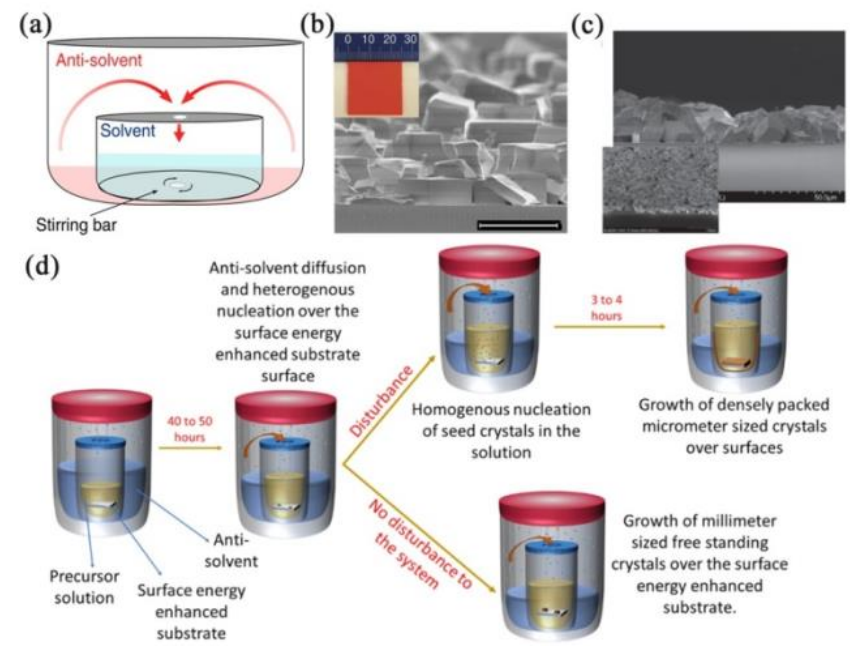

Figure 1. (a) Illustration of the experimental procedure for the growth of large-area microcrystal films. (b) Top-view SEM of a planar-integrated single-crystal perovskite film. The scale bar represents $50 \mathrm{~mm}$. (c) Cross-section and top-view (inset) SEM image of a $\mathrm{MAPbCl}_{3}$ crystalline film. (d) Schematic of the crystallization procedure for antisolvent vapor crystallization (AVC) and sonication-modified AVC. (a)\&(b) Reproduced with permission. ${ }^{84}$ Copyright 2015, Springer Nature, reproduced without any modification and licensed under CC BY 4.0, https://creativecommons.org/licenses/by/4.0/. (c) Reproduced with permission. ${ }^{85}$ Copyright 2016, Wiley-VCH. (d) Reproduced with permission. ${ }^{86}$ Copyright 2019, American Chemical Society.

Perovskite microcrystals measuring tens of micrometers exhibit optoelectronic properties comparable to those of perovskite bulk crystals, the capacity for large-area production, and easy integration onto patterned substrates. In 2015, Liao et al. reported the growth of $\mathrm{MAPbBr}_{3}$ microcrystals on glass slides by a facile one-step solution selfassembly method and realized a built-in whispering-gallery mode microresonator with a high cavity quality factor in the obtained individual square microcrystals of 
$\mathrm{MAPbBr} 3 .{ }^{87}$ Furthermore, via laser-induced heating of liquid precursors, Arciniegas et

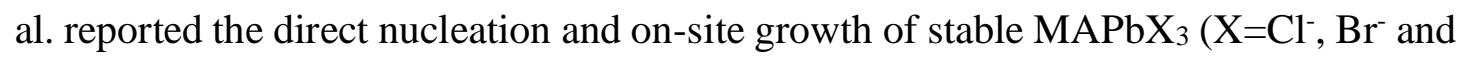
$\mathrm{I}^{-}$) microcrystals on a flat substrate with controlled size; their system also allows for different geometries (arrays of dots, squared, and wires) to be written onto a substrate in seconds by controlling the laser parameters. ${ }^{88}$ Production of large-area perovskite crystal films on substrates is a prerequisite for practical applications, such as imaging. To obtain a large-area crystalline film made up of microcrystals, perturbation is necessary to increase the number of nucleation sites in the crystal growth solution. ${ }^{89-92}$ In 2015, Saidaminov et al. reported the fabrication of large-area, planar-integrated $\mathrm{MAPbBr} 3$ films composed of continuously connected microcrystals on patterned ITO substrates by perturbing the standard antisolvent vapor-assisted crystallization process with the assistance of a stirring force (Figure 1a). ${ }^{84}$ As shown in Figure 1b, the structures obtained - interconnected $\mathrm{MAPbBr}_{3}$ microcrystals measuring 30-50 $\mu \mathrm{m}-$ showed properties comparable to those of free-standing bulk crystals. More interestingly, the resulting photodetector performance was much higher than that of photodetectors based on $\mathrm{MAPbBr} 3$ bulk crystals, likely due to the intimate contact between the microcrystals and substrates as well as the small channel width. Adinolfi et al. adapted this method to the preparation of $\mathrm{MAPbCl}_{3}$ microcrystal films and fabricated high-performance visible-blind UV photodetectors (Figure 1c) ${ }^{85}$ In addition to stirring, sonication is an effective strategy for perturbing the saturated solution to obtain large numbers of nucleation sites. Ahmad et al. introduced homogeneously nucleated seed crystals into a precursor solution by perturbing the system using 
sonication; as a result, the closely packed microcrystals could directly grow on surfacemodified substrates (Figure 1d). ${ }^{86}$ This scalable, substrate-independent crystallization process can be employed to fabricate arrays of planar optoelectronic devices.

\section{Single crystal thin films}

To exploit perovskite crystals for photovoltaic and optoelectronic applications, perovskite single-crystal thin films (SCTFs) of good quality and with thicknesses below the carrier diffusion length are required. ${ }^{73,93-95}$ Advancements in the development of SCTFs over the past three years have boosted the efficiency of single-crystal perovskite solar cells to over $21 \%^{96,97}$. In one of the earliest reports on the subject, Bakr et al. described the growth of perovskite SCTFs by using a cavitation-triggered asymmetrical crystallization method. ${ }^{98}$ As shown in Figure 2, a very short ultrasonic pulse was introduced into the perovskite solution, which reached a low supersaturation level by the slow diffusion of antisolvent vapor. The ultrasound induced cavitation, with the collapse of cavities generating a strong shearing force that resulted in the asymmetric growth of single crystals. Figure $2 \mathrm{~b}$ shows that the obtained SCTFs were composed of a substrate-contacted single-crystal layer without grain boundaries, the thickness of which could be easily controlled from $1 \mu \mathrm{m}$ to $60 \mu \mathrm{m}$ by adjusting the growth time and solution concentration. However, this method only worked for bromide-based perovskite SCTFs, which resulted in low efficiency due to the large band gap of bromide-based perovskites. 

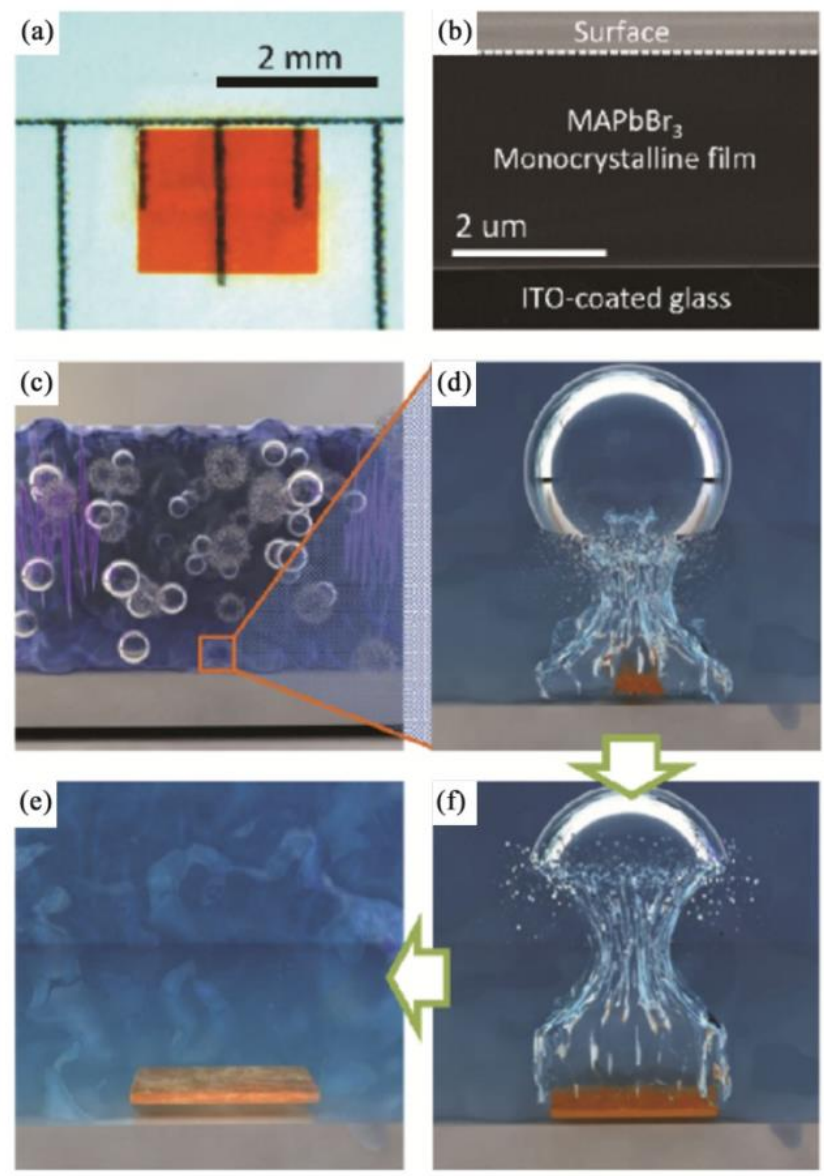

Figure 2. (a) Optical image and (b) cross-sectional SEM image of a single-crystal film. (c)-(f) Illustrations of the CTAC mechanism on a microscopic scale. (a)-(f) Reproduced with permission. ${ }^{98}$ Copyright 2016, Wiley-VCH.

Saidaminov et al. reported the use of geometric confinement to control the shape of single crystals of both bromide-based and iodide-based perovskites by inverse temperature crystallization (ITC) ${ }^{41}$. Meanwhile, Liu et al. demonstrated that spaceconfining ITC enabled the growth of thickness-controlled iodide-based perovskite SCTFs (which have a narrow band gap) that are useful for single-junction solar cells. As shown in Figure 3a, an ultrathin geometry-defined dynamic flow microreactor system was built by separating two thin glass slides with two spacers, to confine the crystal growth within the slit channel. ${ }^{74}$ The thickness of the resulting $\mathrm{MAPbI}_{3} \mathrm{SCTFs}$ 
was controlled from $150 \mu \mathrm{m}$ to $1440 \mu \mathrm{m}$ by adjusting the gap between the two thin glass slides (Figures 3c-f). To further decrease the thickness of the MAPbI 3 SCTFs for photovoltaic applications, ion diffusion in the confined space was accelerated with the assistance of hydrophobic substrates. As shown in Figure 4, millimeter-sized $\mathrm{MAPbI}_{3}$ SCTFs with a tunable thickness ranging from $10 \mu \mathrm{m}$ to $40 \mu \mathrm{m}$ were obtained by Huang et al. in 2017. ${ }^{1}$ The successful reduction in thickness of $\mathrm{MAPbI}_{3} \mathrm{SCTF}$ led to a significant improvement in the photovoltaic efficiency to $17.8 \%$, a record for singlecrystal perovskite solar cells. Subsequently, the space-confined method was demonstrated to be applicable to other perovskite materials, including $\mathrm{MAPbBr}_{3}$ and $\mathrm{MAPbCl}_{3} .{ }^{99,100}$ In addition to improving thickness and composition control, Bakr et al. improved crystal quality by growing $\mathrm{MAPbI}_{3}$ SCTFs in a $\mathrm{N}_{2}$ atmosphere. ${ }^{96}$ They also devised a solvent-engineering approach to reduce the crystallization temperature of $\mathrm{MAPbI}_{3}$ single-crystal films $\left(<90{ }^{\circ} \mathrm{C}\right)$, which yielded higher-quality films with longer carrier lifetimes, thus achieving the current record efficiency of $\sim 21.9 \%$ for singlecrystal perovskite solar cells. ${ }^{97}$ 
(a)

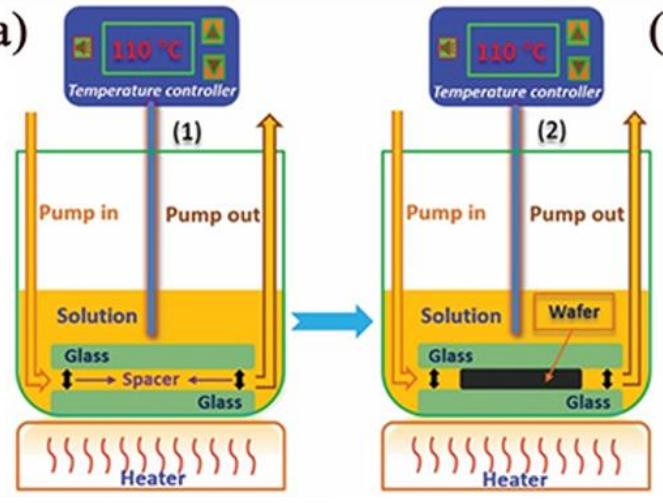

(b)

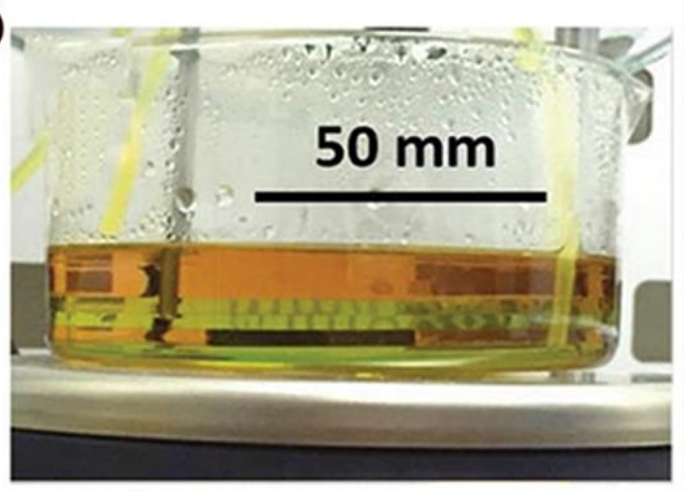

(c)

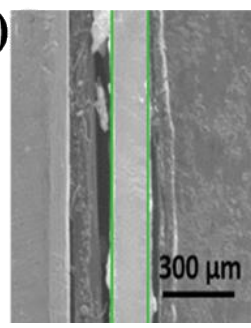

(d)

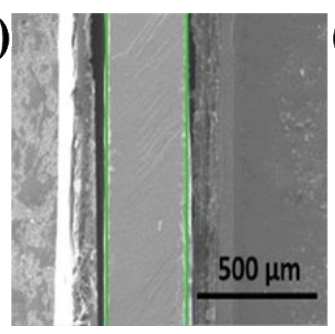

(e)

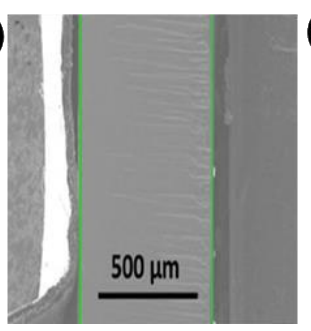

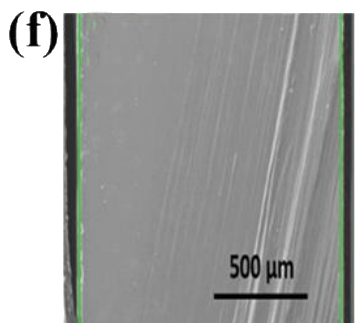

Figure 3. (a) Schematic of the preparation procedure for an ultrathin single-crystal wafer. (b) Photograph of a single-crystal wafer growing in the microreactor system. (c)(f) Cross-sectional optical images of single-crystal perovskite wafers with thicknesses of (c) $\sim 150 \mu \mathrm{m}$, (d) $\sim 330 \mu \mathrm{m}$, (e) $\sim 670 \mu \mathrm{m}$, and (f) $\sim 1440 \mu \mathrm{m}$. Reproduced with permission. ${ }^{74}$ Copyright 2016, Wiley-VCH.

Unfortunately, the abovementioned strategies usually result in only millimetersquared perovskite SCTFs, which are too small to satisfy the standards for practical solar cell applications. To address this shortcoming, Lee et al. took inspiration from the hot-casting and lateral crystal growth techniques to develop a one-step roll-imprinting method to fabricate wafer-scale MAPbI3 SCTFs. ${ }^{101}$ Briefly, a perovskite ink solution was transferred via a channel-patterned rolling mold onto a heated substrate, and largearea SCTFs with controlled orientation were then obtained (Figure 4b). Another universal method for obtaining large-area perovskite SCTFs is the top-down method, which starts with a perovskite bulk single crystal and reduces its dimensions via slicing 
or etching. Liu et al. obtained a series of perovskite SCTFs by slicing bulk single crystals using a diamond-wire slicing machine (Figure 4c); the starting materials included $\mathrm{FAPbI}_{3}, \mathrm{MAPbI}_{3}, \mathrm{MAPbBr}, \mathrm{MAPbCl}_{3}$, and dual-halide crystals made of $\operatorname{MAPb}\left(\mathrm{Cl}_{\mathrm{x}} \mathrm{Br}_{1-\mathrm{x}}\right)_{3}$ and $\mathrm{MAPb}\left(\mathrm{Br}_{\mathrm{x}} \mathrm{I}_{1-\mathrm{x}}\right)_{3} .{ }^{102,103}$

(a)

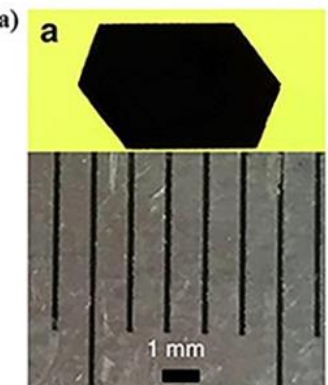

c
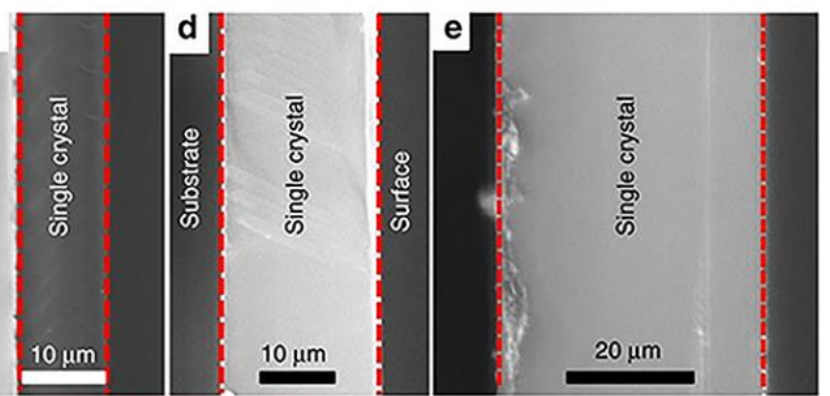

(b)

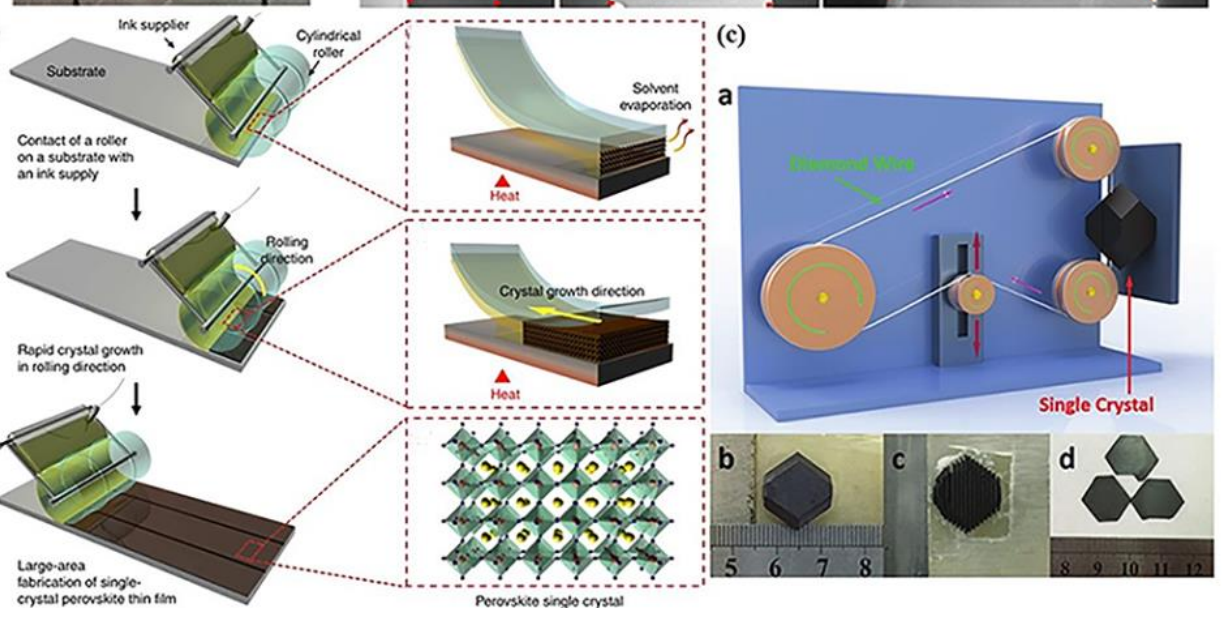

Figure 4. (a) Photographs of a $\mathrm{MAPbI}_{3}$ thin single crystal grown by the space-confined method and cross-sectional SEM images of $\mathrm{MAPbI}_{3}$ thin single crystals with different thicknesses: $\sim 10 \mu \mathrm{m}, \sim 20 \mu \mathrm{m}$, and $\sim 40 \mu \mathrm{m}$. (b) Fabrication of single-crystal perovskite patterned thin film using geometrically confined lateral crystal growth with a rolling mold. (c) Schematic illustrations of top-down strategy for preparing perovskite SCTFs. (a) Reproduced with permission. ${ }^{1}$ Copyright 2017 , Springer Nature, reproduced with rearrangement of the figure and licensed under CC BY 4.0, https://creativecommons.org/licenses/by/4.0/. (b) Reproduced with permission. ${ }^{101}$ Copyright 2017, Springer Nature, reproduced without any modification and licensed 
under CC BY 4.0, https://creativecommons.org/licenses/by/4.0/. (c) Reproduced with permission. ${ }^{103}$ Copyright 2016, Wiley-VCH.

\section{Micro-/nanoplates}

Among various building blocks, micro-/nanoplates have been deemed desirable candidates for the design and construction of integrated electronic or optoelectronic applications. ${ }^{104-111}$ The unique morphological characteristics of these structures render them vulnerable to strong quantum confinement and steric anisotropy effects, which result in superb electrical and photophysical properties beyond those of their bulk counterparts. Hitherto, dedicated efforts have met with exciting success, especially for applications involving lasers and quantum emitters. ${ }^{58,64,112-114}$ To date, methods for synthesizing perovskite micro-/nanoplates can be roughly classified into three types: vapor-phase, solution-phase, and solution-vapor-phase methods.

\subsection{Vapor-phase method}


(a)

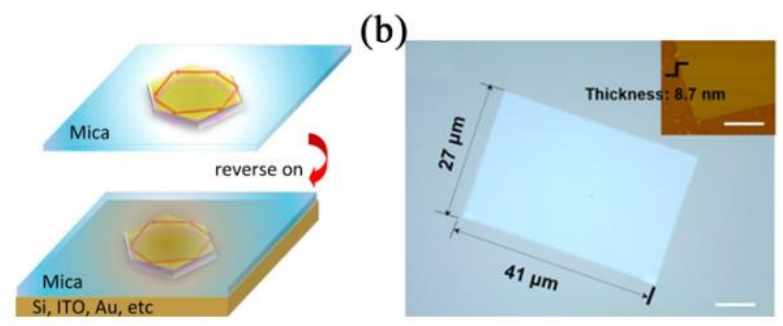

(c)

(d)
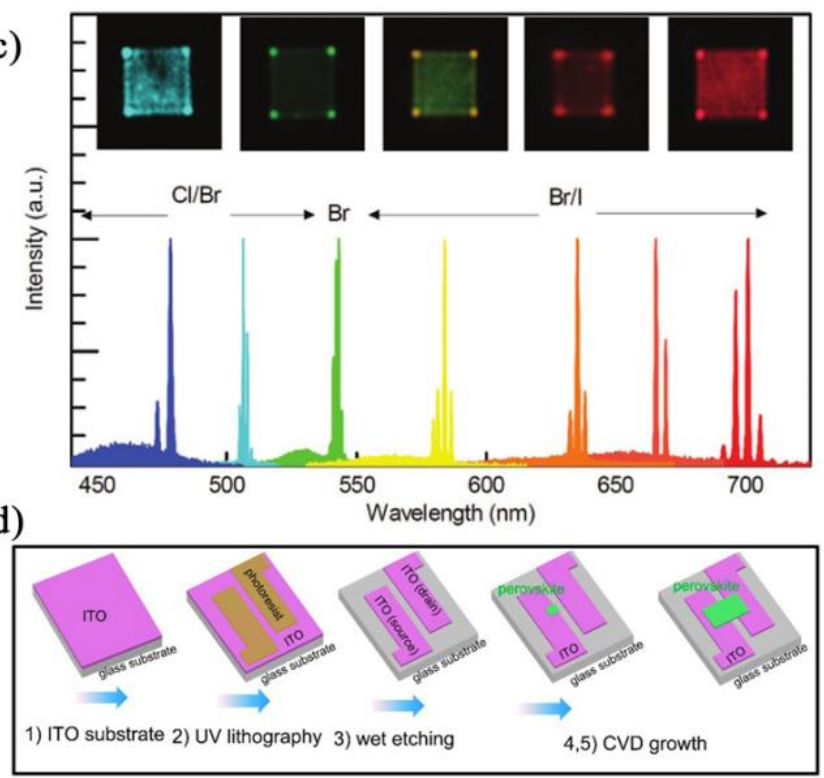

Figure 5. (a) Illustration of the integration process for a perovskite nanolaser device onto different substrates, such as $\mathrm{Si}, \mathrm{Au}$, and ITO bases. (b) Optical microscopy images of as-prepared platelets measuring sub-10 $\mathrm{nm}$ in thickness and several micrometers in lateral length on mica substrate. (c) Lasing images and spectra collected for individual $\mathrm{CsPbX}_{3}$ perovskite nanoplatelets with various halide ions. (d) Schematic of the fabrication processes for a single EL nanodevice with the configuration ITO/CsPbBr3 nanoplate/ITO. (a) Reproduced with permission. ${ }^{112}$ Copyright 2014, American Chemical Society. (b) Reproduced with permission. ${ }^{113}$ Copyright 2015, American Chemical Society. (c) Reproduced with permission. ${ }^{33}$ Copyright 2016, Wiley-VCH. (d) Reproduced with permission. ${ }^{64}$ Copyright 2017, American Chemical Society.

Chemical vapor deposition (CVD) has long been recognized as a widely used and reliable method for preparing ultrathin high-quality 2D nanomaterials with controllable 
size and thickness on certain substrates, including graphene, metal carbides, and layered transition metal dichalcogenides. ${ }^{115}$ With the surge in interest in perovskites, attempts have also been made to synthesize micro-/nanoplates by the vapor-phase method. ${ }^{33}, 60$, 64, 112, 113 In 2014, Zhang et al. fabricated $\mathrm{CH}_{3} \mathrm{NH}_{3} \mathrm{PbI}_{3-\mathrm{a}} \mathrm{X}_{\mathrm{a}}\left(\mathrm{X}=\mathrm{Br}^{-}, \mathrm{Cl}^{-}\right.$, and $\left.\mathrm{I}^{-}\right)$ perovskite nanoplatelets converted from pre-grown lead halide $\mathrm{PbX}_{2}$ platelets on muscovite mica by using a two-step vapor-based method; in this approach, the perovskite nanoplatelet shapes were essentially determined by the $\mathrm{PbX}_{2}$ morphology (triangular or hexagonal platelets). ${ }^{12}$ The well-defined polygonal shape of the resulting high-quality nanoplatelets ensured their function as whispering-gallery-mode (WGM) nanocavities and, in particular, can be potentially integrated onto other conductive bases (such as $\mathrm{Si}, \mathrm{Au}$, and ITO), as shown in Figure 5a. However, it should be noted that the two-step synthesis method is more prone to impurities and defects owing to the insufficient or overreacted conversion process. To solve this problem, Wang et al. established an efficient one-step CVD method. ${ }^{113}$ Via van der Waals epitaxial growth, well-defined rectangular $\mathrm{MAPbCl}_{3}$ platelets could be deposited on muscovite mica substrates with dual precursor sources $\left(\mathrm{PbCl}_{2}\right.$ and $\left.\mathrm{MACl}\right)$ simultaneously in the researchers' CVD system. The as-prepared platelets approached sub-10 nm thicknesses and lateral lengths of several micrometers (Figure 5b). More recently, by adopting the same one-step vapor transport CVD method, Xiong et al. realized well-defined squareshaped all-inorganic $\mathrm{CsPbX}_{3}$ nanoplatelets on muscovite mica substrates, and multicolor lasing action was successfully achieved in the naturally formed nanoplatelet WGM microcavities (Figure 5c) ${ }^{33}$ Furthermore, to overcome the obstacles associated 
with fabricating perovskite nanodevices using traditional lithographic techniques, $\mathrm{CsPbBr}_{3}$ nanoplate-based electroluminescence devices were fabricated on top of two pre-patterned ITO electrodes using the CVD method (Figure 5d); the devices had lateral dimensions of several to a few tens of micrometers and a thickness of 100-500 nm. ${ }^{64}$ Such a direct growth method for preparing perovskite nanostructures could advance their application in on-chip integrated photonics circuits and systems.

\subsection{Solution-phase method}

(a)

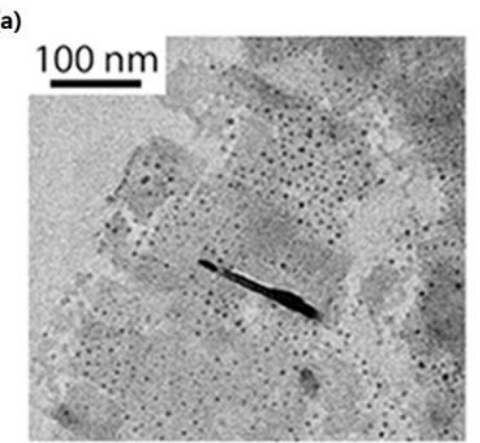

(d)

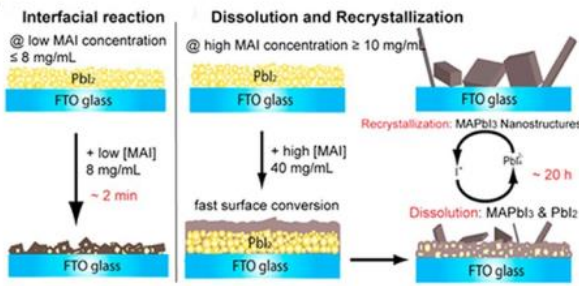

(b)

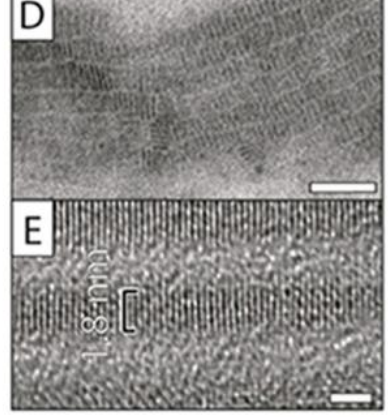

(e) (c)
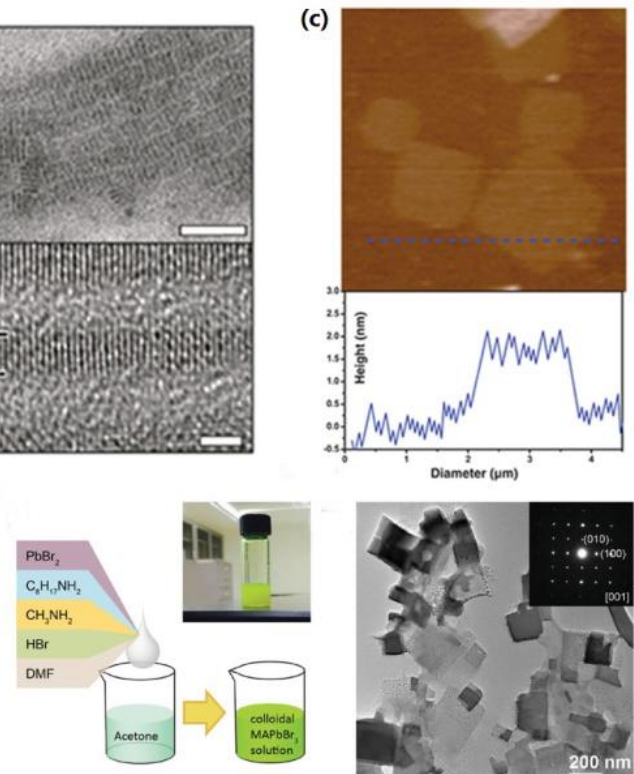

Figure 6. (a) Transmission electron microscopy (TEM) image of unpurified $\mathrm{MAPbBr} 3$ nanocrystals with various morphologies. (b) TEM and high-resolution TEM images of 3-monolayer-thick $\mathrm{CsPbBr}_{3}$ nanoplatelets, indicating a thickness of $1.8 \mathrm{~nm}$. (c) Atomic force microscopy image and height profile of $2 \mathrm{D}\left(\mathrm{C}_{4} \mathrm{H}_{9} \mathrm{NH}_{3}\right)_{2} \mathrm{PbBr}_{4}$ crystals with several single layers. (d) Schematic illustrations of the two growth mechanisms of crystalline $\mathrm{MAPbI}_{3}$ nanostructures. (e) Scheme of one-pot synthesis of $\mathrm{MAPbBr}_{3}$ nanoplatelets (Inset: a photograph of the colloidal solution formed) and TEM images and selected-area diffraction pattern of colloidal $\mathrm{MAPbBr} 3$ nanoplatelets. (a) 
Reproduced with permission. ${ }^{116}$ Copyright 2015, American Chemical Society. (b) Reproduced with permission. ${ }^{117}$ Copyright 2016, American Chemical Society. (c) Reproduced with permission. ${ }^{150}$ Copyright 2015, AAAS. (d) Reproduced with permission. ${ }^{76}$ Copyright 2015, American Chemical Society. (e) Reproduced with permission. ${ }^{118}$ Copyright 2016, Wiley-VCH.

The solution method is another well-established and low-cost way of preparing nano/microplates ${ }^{63,76,87,116,118-120}$. This approach can yield ultrathin (several nanometers) plates, making the most out of the quantum confinement effect. In 2015, Tyagi et al. initiated the synthesis of $\mathrm{MAPbBr} 3$ nanostructures in a mixture with coexisting nanoscale particles and 2D nanoplatelets in the solution phase by using a colloidal approach (Figure 6a). ${ }^{116}$ Pure $\mathrm{MAPbBr} 3$ colloidal platelets were ultimately acquired upon centrifugation from toluene that contained redispersed reaction precipitates, approaching a thickness of $1.2 \mathrm{~nm}$ - as small as a single unit cell. However, the result is debatable, as the small spherical particles may have also been the degradation product of nanoplates under the electron beam due to their very small thickness. Subsequently, Akkerman et al. successfully obtained thickness-controllable $\mathrm{CsPbBr} 3$ nanoplatelets measuring 3 to 5 unit cells by a modified room-temperature colloidal synthesis approach (Figure 6b). ${ }^{117}$ In this method, low reaction temperature and injected acetone play key roles in shape control. It was found that only acetone could trigger the nucleation of platelets, while other solvents facilitated nanocrystal nucleation and growth. Moving beyond methods based on colloidal chemistry, as shown in Figure 6c, Dou et al. demonstrated a modified solid-state crystallization method for producing 
ultrathin $2 \mathrm{D}\left(\mathrm{C}_{4} \mathrm{H}_{9} \mathrm{NH}_{3}\right)_{2} \mathrm{PbBr}_{4}$ nanoplatelets directly on flat substrates by carefully controlling the solvent composition, giving rise to a new way to study perovskites at an atomically thin level. ${ }^{150}$ To improve the compatibility of micro-/nanoplates in future device applications, Jin et al. developed a method for the in situ growth of singlecrystalline $\mathrm{MAPbX}_{3}\left(\mathrm{X}=\mathrm{Br}^{-}, \mathrm{I}^{-}\right)$nanoplates by facile solution conversion from lead iodide (and lead acetate) films to $\mathrm{MAPbI}_{3}$ and $\mathrm{MAPbBr}_{3}$ following the dissolutionrecrystallization growth mechanism (Figure 6d). ${ }^{76}$ Such a solid-liquid interfacial conversion reaction is feasible for preparing nanostructured-perovskite films for photovoltaic and optoelectronic devices. However, the unavoidable pinholes that form in such films can cause serious recombination, resulting in decreased device performance. In 2016, Gao and coworkers produced $\mathrm{MAPbBr} 3$ nanoplates with a narrow spectral band and a high PLQY of $85 \%$; the light emitter based on these perovskite nanoplatelets is one of the brightest perovskite LEDs reported to date. ${ }^{118}$ As shown in Figure 6e, MAPbBr 3 nanoplates were synthesized by a modified ligandassisted precipitation method in which octylammonium bromide was used as the longchain capping ligand, which was determined to be critical to the formation of the nanoplatelet morphology. Such surface-passivated perovskite nanoplatelet-based emitter layers can be readily transferred onto a substrate by spin-coating, inkjet printing, and microcontact printing and other cost-effective deposition methods, offering promising approaches for scalable, high-throughput production technology. However, it is desirable to optimize the synthesis and deposition conditions involved in preparing these perovskite nanoplatelets, such as surface coverage and roughness, to achieve even 
better device performance.

\subsection{Solution-vapor-phase method}

(a)
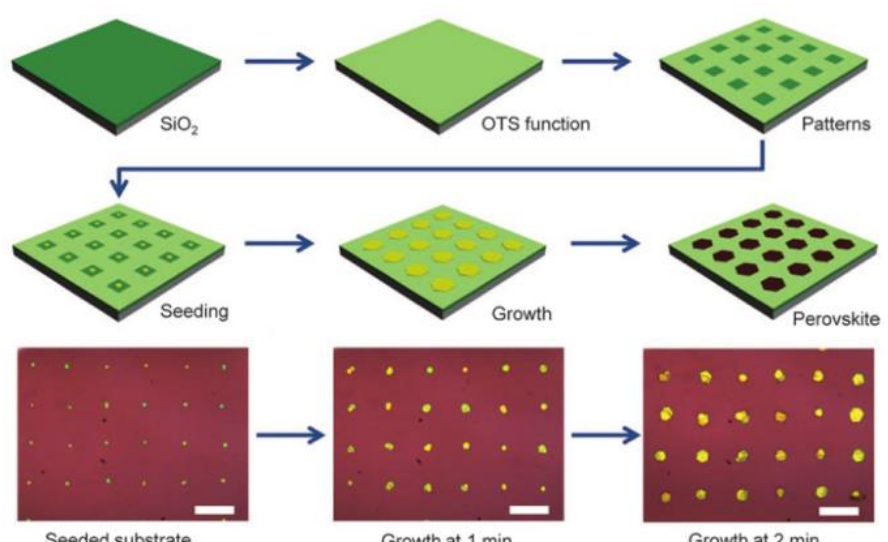

(b)

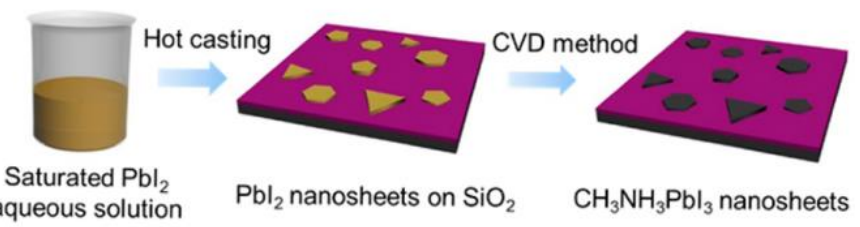

Figure 7. (a) Schematic of the growth of patterned regular arrays of methylammonium lead iodide perovskite microplate crystals. (b) Illustration of the growth of 2D $\mathrm{CH}_{3} \mathrm{NH}_{3} \mathrm{PbI}_{3}$ perovskite nanosheets using a combination of solution and vapor-phase conversion methods. (a) Reproduced with permission. ${ }^{58}$ Copyright 2015, AAAS. The Authors, some rights reserved; exclusive licensee American Association for the Advancement of Science, reproduced without any modification and licensed under CC BY-NC 4.0, https://creativecommons.org/licenses/by-nc/4.0/. (b) Reproduced with permission. ${ }^{121}$ Copyright 2016, American Chemical Society.

Due to the easy growth of $\mathrm{PbI}_{2}$ from an aqueous solution in hydrophilic regions, $\mathrm{PbI}_{2}$ platelets can be selectively grown in periodic arrays on hydrophobic $\mathrm{Si} / \mathrm{SiO}_{2}$ substrates. Therefore, it is easy to grow patterned $\mathrm{MAPbI}_{3}$ perovskite microplate crystals converted 
from $\mathrm{PbI}_{2}$ using a subsequent MAI vapor-phase method for integrated device arrays. Wang et al. presented the first successful patterned growth of single-crystalline $\mathrm{MAPbI}_{3}$ microplates using a facile low-temperature solution method combined with vaporphase treatment. ${ }^{58}$ As shown in Figure 7a, the obtained patterned microplates showed controlled spatial location and periodic arrangement over a large area. This method for the direct growth of patterned arrays is a timely one that solves the urgent challenges associated with the incompatibility of perovskite crystals with typical lithographic processes. Soon after Wang et al. presented their work, Bao and coworkers reported further reducing the thickness of $2 \mathrm{D} \mathrm{CH}_{3} \mathrm{NH}_{3} \mathrm{PbX}_{3}\left(\mathrm{X}=\mathrm{Cl}^{-}, \mathrm{Br}^{-}\right.$, or $\left.\mathrm{I}^{-}\right)$perovskite nanosheets to a single unit cell using a combination of solution- and vapor-phase conversion methods (Figure 7b). ${ }^{121}$ Specifically, the two-step method involves the nucleation of $2 \mathrm{D} \mathrm{PbI}_{2}$ nanosheets on a substrate and the subsequent intercalation of $\mathrm{CH}_{3} \mathrm{NH}_{3} \mathrm{I}$ into the interstitial sites of $\mathrm{PbI}_{6}$ octahedron layers. Because single- or fewunit-cell thicknesses can be achieved, the nanosheets can attain higher photoluminescence quantum yields (PLQYs), outperforming bulk crystals and achieving superior photodetection performance.

\section{Micro-/nanorods}

Compared with 2D micro-/nanoplates, 1D micro-/nanorods feature a higher degree of anisotropy, which provides a high-speed channel for the directional transport and propagation of charge carriers and photons. By taking advantage of such unique characteristics, 1D micro-/nanorods with intriguing electrical and photophysical properties have been demonstrated, attracting interest not only for fundamental studies 
but also for various practical applications.

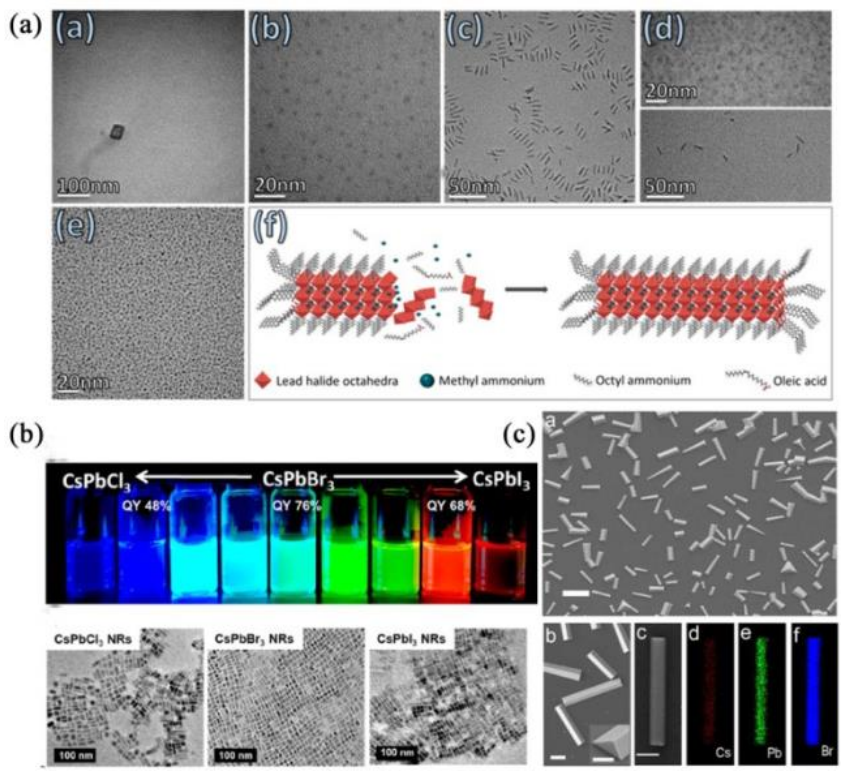

Figure 8. (a) TEM image of $\mathrm{MAPbI}_{3}$ quantum dots/NRs prepared at various OAI/OAc ratios and schematic illustration of the suggested NR formation mechanism. (b) Photograph of respective $\mathrm{CsPbX}_{3}\left(\mathrm{X}=\mathrm{Cl}^{-}, \mathrm{Br}^{-}\right.$, and $\left.\mathrm{I}^{-}\right) \mathrm{NR}$ solutions under 365-nm UV lamp irradiation and representative TEM images of the short $\mathrm{CsPCl}_{3}$ and $\mathrm{CsPbI}_{3} \mathrm{NRs}$ obtained from the pristine short $\mathrm{CsPBr}_{3} \mathrm{NRs}$ by anion exchange. (c) SEM image of as-grown $\mathrm{Cs} \mathrm{PbBr}_{3}$ perovskite nanostructures and corresponding EDX mapping. (a) Reproduced with permission. ${ }^{122}$ Copyright 2016, American Chemical Society. (b) Reproduced with permission. ${ }^{123}$ Copyright 2019, American Chemical Society. (c) Reproduced with permission. ${ }^{65}$ Copyright 2017, American Chemical Society.

As established in the employed protocols for the synthesis of semiconductor nanocrystals, the presence of surfactant molecules in colloidal solutions plays a significant role in controlling nanocrystal shape; in particular, the specific adsorption of these molecules onto individual crystallographic planes can alter the relative growth 
rates of different facets. ${ }^{82,124}$ Inspired by such frequently used colloidal methods, Aharon and Etgar presented a solution-based growth method, synthesizing 1D $\left(\mathrm{C}_{8} \mathrm{H}_{17} \mathrm{NH}_{3}\right)_{2}\left(\mathrm{CH}_{3} \mathrm{NH}_{3}\right)_{2} \mathrm{~Pb}_{3}\left(\mathrm{I}_{\mathrm{x}} \mathrm{Br}_{1-\mathrm{x}}\right)_{10}(0>\mathrm{x}>1)$ nanorods with a highly uniform size distribution of a few nanometers in width and tens of nanometers in length. ${ }^{122}$ Both octylammonium iodide (OAI) and oleic acid (OAc) were used in these syntheses. With the help of iodine ions, OAI attached its alkyl chain to specific sites on the perovskite surface through "chemisorption" to inhibit growth in a particular direction, while OAc interacted with the perovskite interface through weaker "physisorption". This difference in adsorption affinity between the ligands toward the perovskite surface is essential for the formation of nanorods. The formation of pure NRs was achievable only at a balanced $\mathrm{OAI} / \mathrm{OAc}$ ratio; either a high or low ratio would result in the formation of quantum dots or a mixture of quantum dots and nanorods (Figure 8a). Very recently, Rogach et al. managed to form $\mathrm{CsPbr}_{3}$ nanorods with a controllable aspect ratio (2 and 5) in polar alcohols using a direct colloidal synthesis. ${ }^{123}$ This reaction for the direct synthesis of $\mathrm{CsPbBr}_{3}$ nanorods is quite flexible, employing a range of short-chain alcohols to serve as the reaction medium, and both $\mathrm{CsPbCl}_{3}$ and $\mathrm{CsPbI}_{3}$ NRs with similar dimensions can be realized by anion exchange, as shown in Figure $\mathbf{8 b}$.

Post-synthetic chemical and shape-transformation processes offer alternative ways to obtain colloidal nanocrystal morphologies that are difficult to synthesize by direct synthetic routes. In 2018, Yu et al. ${ }^{125}$ used a halide ion exchange reaction to fragment $\mathrm{CsPbBr}_{3}$ nanowires into nearly monodisperse low-aspect-ratio $\mathrm{CsPbX}_{3}$ nanorods composed of different halides. The nanorods transformed from nanowires showed 
increased photoluminescence efficiency, which should be due to the reduction in the nonradiative decay rate.

The majority of research efforts have concentrated on solution synthesis routes for all-inorganic perovskite nanostructures, while vapor-phase synthesis has developed at a slower rate. Using an improved vapor deposition method, Pan et al. successfully grew composition-tunable $\mathrm{CsPbX}_{3}$ perovskite micro-/nanorods on $\mathrm{SiO}_{2} / \mathrm{Si}$ substrates; the rods possessed an ultra-smooth surface and well-defined triangular facets (Figure 8c). ${ }^{65}$ These high-quality triangular $\mathrm{CsPbX}_{3}$ micro-/nanorods were fabricated for roomtemperature optically pumped tunable lasing, which covered nearly the entire visible spectral region with low lasing thresholds and high quality factors. However, the method is still being modified to further enhance the growth of perovskite micro/nanorods.

\section{Nanocrystals}

Perovskite nanocrystals (NCs), nanometer-scale perovskite single crystals capped with surfactant molecules and dispersed in non-polar solution, are promising for optoelectronic applications due to their spectral tunability. Through halide composition control and the quantum size effect, the band gap of perovskite NCs is readily tunable over the entire visible spectral region at the point of manufacture. ${ }^{126,92}$ The first perovskite NCs were synthesized in 2014, ${ }^{127}$ and the groups of Kovalenko and Zhong were the first to demonstrate bright lead halide perovskite NCs with high PLQYs of over $90 \%$, narrow emission line widths, wide color gamuts, and short radiative lifetimes. ${ }^{128,129}$ These excellent photophysical properties of perovskite NCs are derived 
mainly from their relatively high defect tolerance, ${ }^{130}$ their suppression of ion migration, and their augmented exciton binding energy achieved by reducing the crystal size.

Although those perovskites that exhibit excellent semiconductor properties belong to the cubic or the orthorhombic phase, the initial perovskite NCs were not square. Note that during the early stages of perovskite NC morphology characterization, the possibility of perovskite NC degradation, caused by the electron beam of the TEM, was not fully accounted for. As shown in Figure 9a, $\mathrm{MAPbBr}_{3} \mathrm{NCs}$ synthesized by injecting a mixture of $\mathrm{MABr}, \mathrm{PbI}_{2}$, and $\mathrm{DMF}$ into oleic acid octadecene solution were spherical. ${ }^{127}$ Later, Zhong and coworkers developed a ligand-assisted reprecipitation (LARP) technique (Figure 9b), which improved the PLQY of round $\mathrm{MAPbBr}_{3} \mathrm{NCs}$ to $70 \%{ }^{128}$. To further improve NC performance, the growth mechanism was investigated, with researchers reporting square perovskite NCs with PLQYs of over 90\%. Zhang et al. investigated how polar solvents influence NC shape and size (Figure 9c) by introducing water into the LARP process, and they correlated the size and crystallinity of the resulting $\mathrm{CsPbBr}_{3} \mathrm{NCs}$ with the water content. ${ }^{126}$ With a suitable amount of water, spherical NCs gave way to rectangular NCs, and the PLQY increased from 50\% to $90 \%$. Another strategy for obtaining rectangular $\mathrm{MAPbBr}_{3} \mathrm{NCs}$ is to provide sufficient energy for NC growth by increasing temperature. As shown in Figure 9d, Paul et al. synthesized $\mathrm{MAPbBr} 3 \mathrm{NCs}$ at $165^{\circ} \mathrm{C}$, producing rectangular rather than spherical NCs with a very high PLQY of $98 \% .{ }^{131}$ 


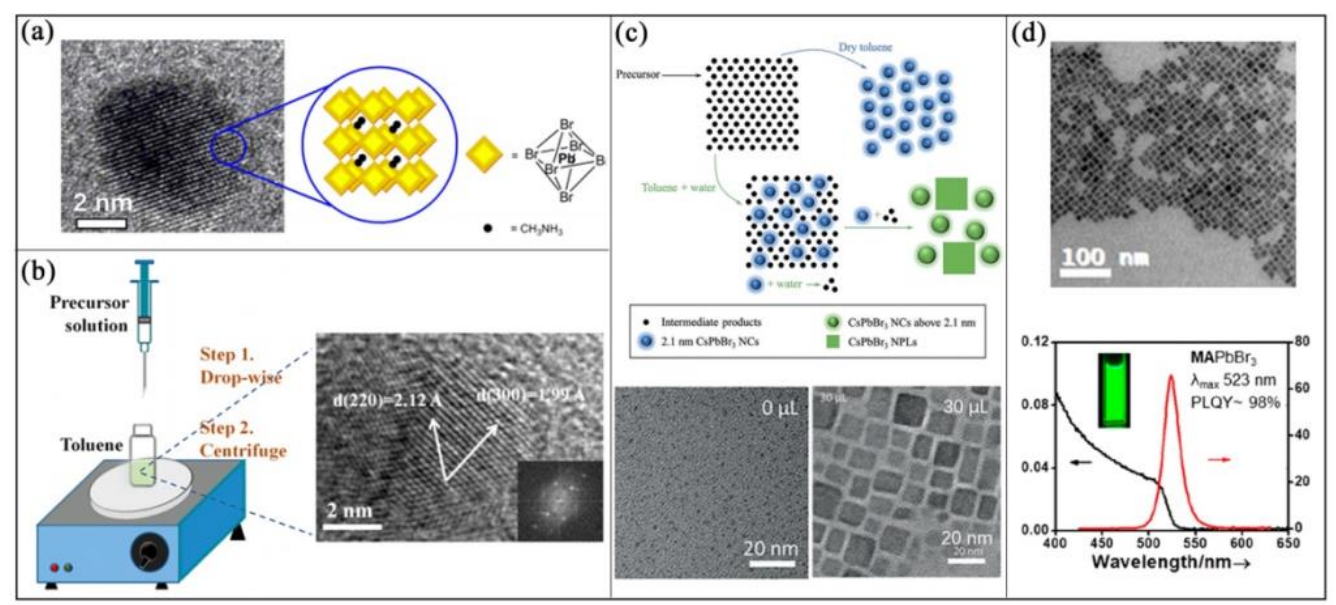

Figure 9. (a) HRTEM image of a $\mathrm{MAPbBr}_{3} \mathrm{NC}$ (scale bar: $2 \mathrm{~nm}$ ) and schematic representation of its crystal structure. (b) Schematic illustration of the LARP process and HRTEM image of the corresponding product. (c) Schematic illustration of the possible water-assisted growth process of $\mathrm{CsPbBr}_{3}$ NCs and TEM images of NCs synthesized with 0 and $30 \mu \mathrm{L}$ water. (d) TEM image and absorption and emission spectra of $\mathrm{MAPbBr} 3 \mathrm{NCs}$ synthesized at $165^{\circ} \mathrm{C}$. The inset at the bottom of (d) shows a photograph of the MAPbBr 3 nanocrystals under UV light. (a) Reproduced with permission. ${ }^{127}$ Copyright 2014, American Chemical Society. (b) Reproduced with permission. ${ }^{129}$ Copyright 2015, American Chemical Society. (c) Reproduced with permission. ${ }^{126}$ Copyright 2018, Wiley-VCH. (d) Reproduced with permission. ${ }^{131}$ Copyright 2020, American Chemical Society.

The morphology of perovskite NCs is highly tunable beyond spherical and rectangular. By introducing phosphonate groups, which offer a stronger binding affinity towards $\mathrm{Pb}^{2+}$ ions, $\mathrm{Cs} \mathrm{PbBr}_{3} \mathrm{NCs}$ in the shape of truncated octahedra can be obtained, with near-unity PLQYs (Figure 10a). ${ }^{132}$ By controlling the dissolution rates of the Cs and $\mathrm{Pb}$ precursors, $\mathrm{CsPbBr}_{3}$ nanoflowers can be obtained (Figure 10b). ${ }^{133}$ Through a 
one-pot synthesis process and by carefully controlling the NC formation rates, $\mathrm{CsPbBr}_{3} @ \mathrm{SiO}_{2}$ perovskite-insular core-shell NCs can be obtained (Figure 10c). ${ }^{134}$ Epitaxial solution growth has been employed to grow perovskite semiconductor coreshell NCs, and $\mathrm{CsPbBr}_{3} @ \mathrm{ZnS}^{135}, \mathrm{CsPbBr}_{3} @ \mathrm{TiO}_{2}{ }^{136}$, and $\mathrm{CsPbI}_{3} @ \mathrm{PbS}^{137}$ core-shell NCs have been obtained. Figure 10d shows a TEM image and EDX spectra of CsPbBr $3 @$ CdS core-shell NCs. ${ }^{138}$ Furthermore, changing the surface ligand species can also alter the shape of perovskite NCs, producing spherical NCs, nanocubes, nanorods, and nanoplatelets (Figure 10e). ${ }^{139}$

(a)

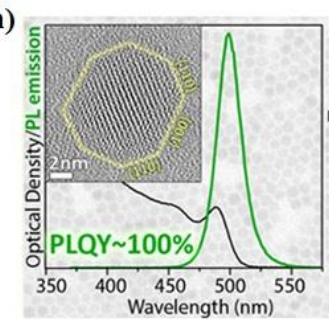

(d)

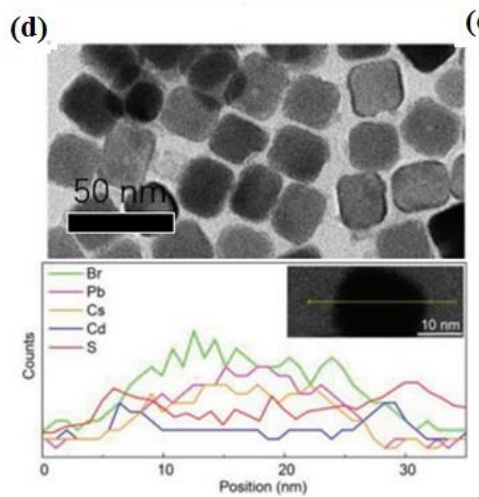

(b)

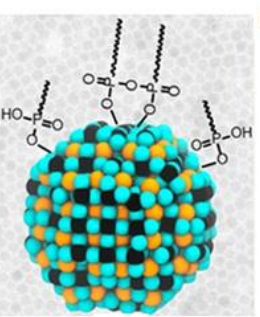

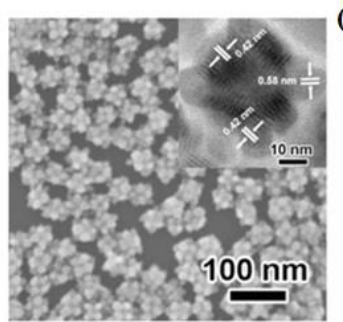

(c)

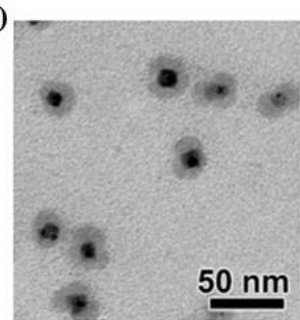

Figure 10. TEM images of (a) truncated-octahedron $\mathrm{CsPbBr} 3 \mathrm{NCs}$, (b) $\mathrm{CsPbBr}_{3}$ nanoflowers, (c) $\mathrm{CsPbBr}_{3} @ \mathrm{SiO}_{2}$ core-shell NCs, and (d) $\mathrm{CsPbBr} 3 @ \mathrm{CdS}$ core-shell NCs. (e) Ligand-mediated synthesis of shaped-controlled perovskite NCs. The inset of (a) also shows the absorbance and PL emission spectra of the $\mathrm{CsPbBr}_{3} \mathrm{NCs}$, as well as a diagram of the truncated-octahedron NCs. (a) Reproduced with permission. ${ }^{132}$ Copyright 2019, American Chemical Society. (b) Reproduced with permission. ${ }^{133}$ 
Copyright 2018, Elsevier. (c) Reproduced with permission. ${ }^{134}$ Copyright 2018, American Chemical Society. (d) Reproduced with permission. ${ }^{138}$ Copyright 2018, Wiley-VCH. (e) Reproduced with permission. ${ }^{139}$ Copyright 2016, American Chemical Society.

Nanorods, nanowires, and nanoplatelets can be obtained by the modulation of suitable capping ligands and the subsequent assembly of nanocrystals. ${ }^{140-142}$ Suitable surface groups that selectively bind to certain facets allow for the oriented growth of perovskites, which leads to $1 \mathrm{D}$ or $2 \mathrm{D}$ nanomaterials. For example, Manna et al. demonstrated that $\mathrm{CsPbBr}_{3}$ nanoplatelets can switch to shape-pure, nearly monodisperse nanocubes when secondary aliphatic amines are introduced. ${ }^{143}$ By decreasing the reaction temperature and prolonging the reaction time, Yang and coworkers were the first group to synthesize orthorhombic $\mathrm{CsPbBr}_{3}$ perovskite nanowires (Figure 11a). ${ }^{106}$ The nanowire length could be controlled by introducing hydrohalic acids $\left(\mathrm{HX}, \mathrm{X}=\mathrm{Cl}^{-}, \mathrm{Br}^{-}, \mathrm{I}^{-}\right)$into the reaction solution, due to the protonation of the oleylamine ligands. As shown in Figure $11 \mathrm{~b}$, by replacing $\mathrm{Cs}^{+}$with the oleylammonium cations at the growing surface during crystallization, the nanowire length was optimized. ${ }^{107}$ Additionally, initially formed $\mathrm{CsPbBr} 3$ nanocubes have shown the ability to transform into nanorods and nanowires through an oriented attachment mechanism. ${ }^{144}$ During the reported transformation, the emission peak position remained nearly unchanged, while a strong polarized emission with a polarization anisotropy of 0.36 appeared. 
(a)

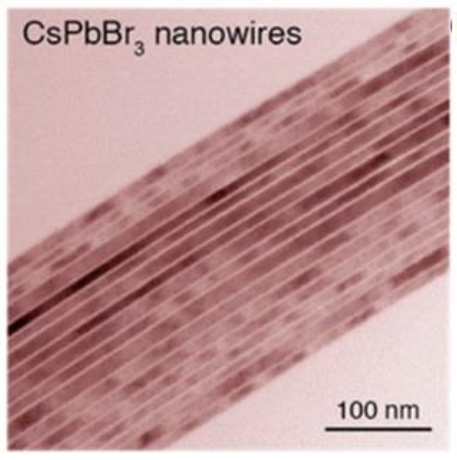

(b)

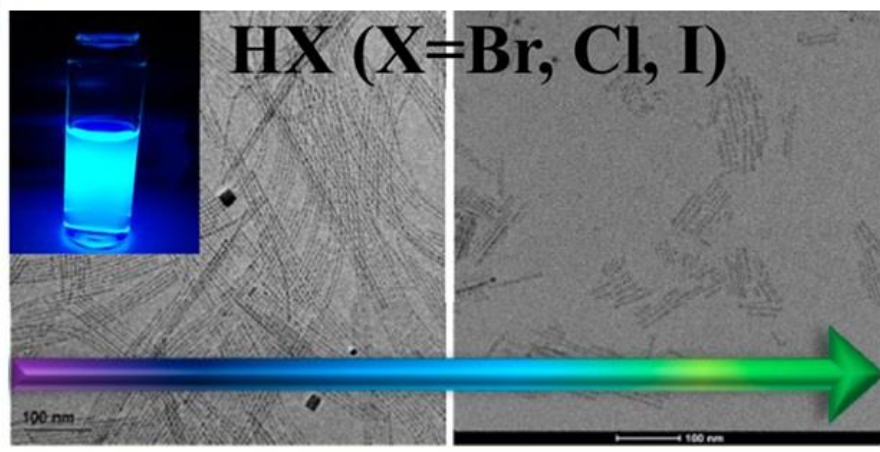

Figure 11. (a) TEM image of $\mathrm{CsPbBr}_{3}$ nanowire. (b) TEM images showing HXassisted length control of perovskite nanowires. The inset of (b) shows a photograph of a $\mathrm{CsPbBr}_{3}$ nanowire under UV light $(\lambda=365 \mathrm{~nm})$. (a) Reproduced with permission. ${ }^{145}$ Copyright 2015, American Chemical Society. (b) Reproduced with permission. ${ }^{146}$ Copyright 2017, American Chemical Society.

\section{Challenges and perspectives}

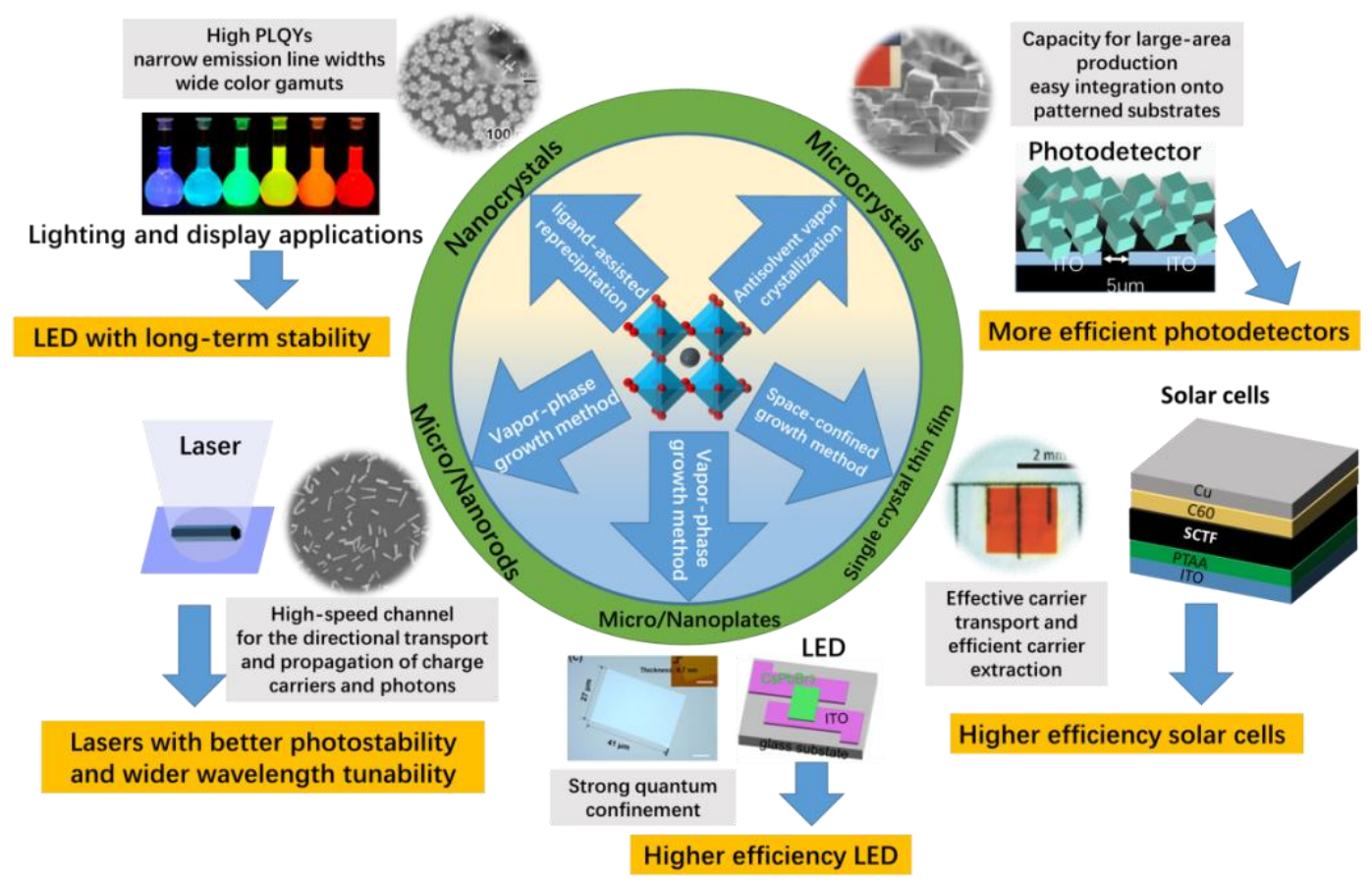

Figure 12. Scheme of growth methods, properties, and perspectives for various shaped-single crystal perovskites. Reproduced with permission. ${ }^{84}$ Copyright 2015, Springer Nature, reproduced without any modification and licensed under CC BY 4.0, 
https://creativecommons.org/licenses/by/4.0/.; Reproduced with permission. $^{98}$ Copyright 2016, Wiley-VCH; Reproduced with permission. ${ }^{113}$ Copyright 2014, American Chemical Society; Reproduced with permission. ${ }^{64}$ Copyright 2017, American Chemical Society; Reproduced with permission. ${ }^{65}$ Copyright 2017 , American Chemical Society; Reproduced with permission. ${ }^{133}$ Copyright 2018, Elsevier; Reproduced with permission. ${ }^{128}$ Copyright 2015, American Chemical Society.

Shape control of MHP single crystals has allowed for the successful tuning of their optoelectronic properties and has expanded their applications (Figure 12). Currently, through the antisolvent vapor crystallization growth method, the microcrystals that are amenable to large-area production can be integrated with patterned substrates and yield the best performance in photoconductive photodetectors. SCTFs grown by the spaceconfined growth method exhibit effective carrier transport and efficient carrier extraction properties, and the optimization of SCTF thickness and crystal quality has led to dramatic performance improvements in single-crystal perovskite solar cells; however, these devices still lag far behind their polycrystalline counterparts. Micro/nanoplates and micro-/nanorods endowed with strong quantum confinement and steric anisotropy effects have found applications in lasers and LEDs. Nanocrystals that exhibit high PLQYs and narrow emission line widths can be prepared by the ligand-assisted reprecipitation method for efficient lighting and display applications. To provide guidelines for the future design of both novel materials and structures of perovskite single crystals and the further development of single-crystal optoelectronic devices, we highlight the following challenges and perspectives. 
1. The surfaces of perovskite single crystals have been demonstrated to show higher charge trap densities than those recorded for bulk crystals and even polycrystalline thin films. This quality greatly hampers the properties of perovskite single crystals and their corresponding device performance. Although a series of strategies have been developed to passivate surface charge traps, these strategies still rarely produce a surface with a trap density comparable to that of the bulk of single crystals. The surface charge traps of perovskite single crystals are likely due to the loss of organic amine ions. Therefore, creating effective techniques for replenishing the organic amine ions on the surface may further improve single crystal quality and device performance.

2. The most widely investigated perovskite single crystals are mainly of the singlecation and halide varieties, such as $\mathrm{MAPbBr} 3, \mathrm{MAPbI}_{3}$, and $\mathrm{FAPbBr}$. Mixed-cation and mixed-halide perovskites have been reported to increase both the efficiency and stability of polycrystalline solar cells. The growth of such mixed perovskite single crystals with different morphologies is a good direction for further increasing the stability of perovskite single-crystal optoelectronic devices.

3. For solar cells, controlling the thickness of perovskite SCTFs is highly important for ensuring effective carrier transport; however, the thickness of millimeter-sized iodidebased SCTFs can hardly reach below $10 \mu \mathrm{m}$ through existing methods. Developing novel methods for growing SCTFs with thicknesses comparable to those of polycrystalline thin films is necessary both for improving efficiency and for gaining a fundamental understanding of the surface and grain boundaries of metal halide perovskite materials. As is the case for solar cells, thickness control is important for 
increasing the response speed of photodiode-type single crystal photodetectors. Reducing the crystal thickness will decrease the transit time but will increase the capacitance of the device simultaneously. Importantly, increasing the resistancecapacitance $(\mathrm{RC})$ constant will conflict with the reduced transit time, which should be considered to achieve the highest response speed.

4. The solid-state PLQY of perovskites is important for both lasers and LEDs. For lasing, determining how to maintain the excellent optical properties of solution-state NCs is important. Polymer matrix and metal oxide shells have been employed but have consistently been accompanied by NC aggregation. Strategies that can generate coreshell structures at the single-particle level are promising for the development of highPLQY solid-state perovskites. For LEDs, decreasing the crystal size will increase the exciton binding energy but can also introduce more surface states (trapping charge carriers) and reduce the carrier diffusion length. Thus, it is important to find a balance between optical properties and crystal size and develop facile and efficient surface passivation strategies.

5. Lead halide perovskite materials will present environmental problems due to the toxicity of lead ions. To address this issue, many lead-free perovskite materials have been developed, such as $\mathrm{Cs}_{2} \mathrm{AgBiBr}_{6}, \mathrm{MA}_{2} \mathrm{TeI}_{6}$, and $\mathrm{FASnI}_{3}$. Nevertheless, their materials properties and corresponding device performance still compete with those of lead halide perovskites. To reduce the toxicity of perovskite materials, novel lead-free perovskite materials should be further explored. Moreover, thickness-controlled singlecrystal solar cells that do not require careful microstructure control of the thin films 
may be good candidates for evaluating the feasibility of lead-free perovskite materials. 6. Improving the efficiency of carrier extraction, suppressing carrier recombination, and reducing the impact of environmental effects, such as moisture, requires intimate interfacial contact between the perovskite crystals and the transport layers and substrates, especially for large-area devices (e.g., photodetectors and solar cells). There is still much room for increasing the contact surface area. Efforts should be devoted to the in-depth investigation of the key factors determining interfacial contact quality, including increasing surface coverage and smoothness and engineering the strains between the single crystal and the adjacent layers.

7. Single-crystal perovskite solar cells may become an alternative perovskite photovoltaic technology if efficient large-area devices can be fabricated. To reach this target, growing high-quality, large-area single-crystal wafers with micrometer thickness is required. Currently, the fabrication of large-area single-crystal wafers relies on a top-down strategy in which bulk single crystals are first grown and then sliced into thin wafers. However, single-crystal wafer thicknesses hardly dip below $100 \mu \mathrm{m}$. In addition to solar cells, large-area single-crystal wafers can also find practical application in the field of medical imaging, wherein-importantly—facile integration with commercial chips should be achieved.

8. In addition to pursuing higher efficiency and better stability, single-crystal solar cells based on perovskite SCTFs are also an area that could lead to many exciting fundamental studies. Sample topics include the nature of surface states, bulk defect states, the role of solvents, diffusion length vs. charge collection in single-crystal 
devices, contact layers, the effect of device fabrication on single-crystal devices, and importantly, the main differences between single-crystal and polycrystalline perovskites. Recent reports have shown that well-passivated perovskite polycrystalline thin films can exhibit properties comparable to those of single crystals. ${ }^{147,148}$ To address this issue, we propose the comparison of solar cells based on single-crystal and polycrystalline thin films with thicknesses ranging from $500 \mathrm{~nm}$ to hundreds of $\mu \mathrm{m}$. We believe this strategy is superior to direct measurement by the transient spectra technique.

9. Combining SCTFs with nanocrystals may provide a promising way towards achieving efficient single-crystal solar cells. Suitable contact layers will maximize the performance of single-crystal solar cells. Nanocrystals with controllable doping properties can show tunable p-type or n-type semiconducting properties, and their varied surface groups can passivate the surface defects of perovskites. ${ }^{149}$ Thus, employing the optimized NC films as the contact layers for single-crystal solar cells will not only provide efficient charge collection pathways but also widen the depletion region and lower the defect density, leading to performance enhancement.

\section{Summary}

As a result of their superior properties, single crystals are slated to be the next evolution in MHP optoelectronic devices. However, with the exception of their application in high-energy radiation detectors, single-crystal MHPs have yet to deliver on their promise for optoelectronic applications-principally, due to the difficulty of integrating them into devices. Fortunately, recent developments in the shape control of 
perovskite single crystals are paving the way for compelling device demonstrations: single-crystal solar cells whose efficiencies are catching up to those of their state-ofthe-art polycrystalline counterparts; micro-crystal-based photodetectors displaying ultra-high sensitivity; and NC-based LEDs exhibiting high EQEs. Through rational shape control of MHP single crystals, the advantages of their intrinsic properties will be within the grasp of optoelectronic researchers in the near future.

\section{Notes}

O. M. B. is a founder of Quantum Solutions (qdot.inc), a nanotechnology company that develops and manufactures quantum dot materials for displays, image sensors, and solar cells.

\section{Author Contributions}

\#A. F and X. J contributed equally to this work.

\section{Acknowledgements}

The authors acknowledge funding support from Shandong University, KAUST, and Saudi Aramco (grant no. RGC/3/3543-01-01).

\section{References}

1. Chen, Z.; Dong, Q.; Liu, Y.; Bao, C.; Fang, Y.; Lin, Y.; Tang, S.; Wang, Q.; Xiao, X.; Bai, Y.; et al. Thin single crystal perovskite solar cells to harvest below-bandgap light absorption. Nat. Commun. 2017, 8, 1890.

2. Huang, J.; Shao, Y.; Dong, Q. Organometal Trihalide Perovskite Single Crystals: A Next Wave of Materials for 25\% Efficiency Photovoltaics and Applications Beyond? $J$. Phys. Chem. Lett. 2015, 6, 3218-3227.

3. Dong, Q.; Fang, Y.; Shao, Y.; Mulligan, P.; Qiu, J.; Cao, L.; Huang, J. Electron-hole diffusion lengths $>175 \mu \mathrm{m}$ in solution-grown $\mathrm{CH}_{3} \mathrm{NH}_{3} \mathrm{PbI}_{3}$ single crystals. Science. 2015, 347, 967-970.

4. Wehrenfennig, C.; Eperon, G. E.; Johnston, M. B.; Snaith, H. J.; Herz, L. M. High Charge Carrier Mobilities and Lifetimes in Organolead Trihalide Perovskites. Adv. 
Mater. 2014, 26, 1584-1589.

5. Adinolfi, V.; Peng, W.; Walters, G.; Bakr, O. M.; Sargent, E. H. The Electrical and Optical Properties of Organometal Halide Perovskites Relevant to Optoelectronic Performance. Adv. Mater. 2018, 30, 1700764.

6. Kojima, A.; Teshima, K.; Shirai, Y.; Miyasaka, T. Organometal Halide Perovskites as Visible-Light Sensitizers for Photovoltaic Cells. J. Am. Chem. Soc. 2009, 131, 60506051.

7. Im, J.-H.; Lee, C.-R.; Lee, J.-W.; Park, S.-W.; Park, N.-G. 6.5\% efficient perovskite quantum-dot-sensitized solar cell. Nanoscale. 2011, 3, 4088-4093.

8. Kim, H.-S.; Lee, C.-R.; Im, J.-H.; Lee, K.-B.; Moehl, T.; Marchioro, A.; Moon, S.-J.; Humphry-Baker, R.; Yum, J.-H.; Moser, J. E.; et al. Lead Iodide Perovskite Sensitized All-Solid-State Submicron Thin Film Mesoscopic Solar Cell with Efficiency Exceeding 9\%. Sci Rep. 2012, 2, 591.

9. Yang, Z.; Yu, Z.; Wei, H.; Xiao, X.; Ni, Z.; Chen, B.; Deng, Y.; Habisreutinger, S. N.; Chen, X.; Wang, K.; Zhao, J.; Rudd, P. N.; Berry, J. J.; Beard, M. C.; Huang, J. Enhancing electron diffusion length in narrow-bandgap perovskites for efficient monolithic perovskite tandem solar cells. Nat. Commun. 2019, 10, 4498.

10. Wang, P.; Wu, Y.; Cai, B.; Ma, Q.; Zheng, X.; Zhang, W. H. Solution-Processable Perovskite Solar Cells toward Commercialization: Progress and Challenges. Adv. Funct. Mater. 2019, 29, 1807661.

11. Zheng, X.; Hou, Y.; Bao, C.; Yin, J.; Yuan, F.; Huang, Z.; Song, K.; Liu, J.; Troughton, J.; Gasparini, N.; et al. Managing grains and interfaces via ligand anchoring enables 22.3\%-efficiency inverted perovskite solar cells. Nat. Energy 2020, 5, 131-140. 12. Best Research-Cell Efficiency Chart | Photovoltaic Research | NREL https:// www.nrel.gov/pv/cell-efficiency.html (accessed April 10, 2020).

13. Jiang, X.; Fu, X.; Ju, D.; Yang, S.; Chen, Z.; Tao, X. Designing Large-Area Single-Crystal Perovskite Solar Cells. ACS Energy Lett. 2020, 5, 1797-1803.

14. Zhang, J.; Hodes, G.; Jin, Z.; Liu, S., All-Inorganic CsPbX3 Perovskite Solar Cells: Progress and Prospects. Angew. Chem. Int. Edit. 2019, 58, 15596-15618.

15. Dou, L.; Yang, Y.; You, J.; Hong, Z.; Chang, W.-H.; Li, G.; Yang, Y. Solution- 
processed hybrid perovskite photodetectors with high detectivity. Nat. Commun. 2014, 5,5404 .

16. Fang, Y.; Dong, Q.; Shao, Y.; Yuan, Y.; Huang, J. Highly narrowband perovskite single-crystal photodetectors enabled by surface-charge recombination. Nat. Photonics. 2015, 9, 679-686.

17. Ahmadi, M.; Wu, T.; Hu, B. A Review on Organic-Inorganic Halide Perovskite Photodetectors: Device Engineering and Fundamental Physics. Adv. Mater. 2017, 29. 1605242.

18. Wang, H.; Kim, D. H. Perovskite-based photodetectors: materials and devices. Chem. Soc. Rev. 2017, 46, 5204-5236.

19. Song, J.; Cui, Q.; Li, J.; Xu, J.; Wang, Y.; Xu, L.; Xue, J.; Dong, Y.; Tian, T.; Sun, H.; et al. Ultralarge All-Inorganic Perovskite Bulk Single Crystal for High-Performance Visible-Infrared Dual-Modal Photodetectors. Adv. Opt. Mater. 2017, 5, 1700157.

20. Shaikh, P. A.; Shi, D.; Retamal, J. R. D.; Sheikh, A. D.; Haque, M. A.; Kang, C. F.; He, H.; Bakr, O. M.; Wu, T. Schottky junctions on perovskite single crystals: lightmodulated dielectric constant and self-biased photodetection. J. Mater. Chem. C 2016, 4, 8304-8312.

21. Saidaminov, M. I.; Haque, M. A.; Almutlaq, J.; Sarmah, S.; Miao, X.-H.; Begum, R.; Zhumekenov, A. A.; Dursun, I.; Cho, N.; Murali, B.; et al. Inorganic Lead Halide Perovskite Single Crystals: Phase-Selective Low-Temperature Growth, Carrier Transport Properties, and Self-Powered Photodetection. Adv. Opt. Mater. 2017, 5, 1600704.

22. Yang, C.; El-Demellawi, J. K.; Yin, J.; Velusamy, D. B.; Emwas, A.-H. M.; El-Zohry, A. M.; Gereige, I.; AlSaggaf, A.; Bakr, O. M.; Alshareef, H. N.; et al. $\mathrm{MAPbI}_{3}$ Single Crystals Free from Hole-Trapping Centers for Enhanced Photodetectivity. ACS Energy Lett. 2019, 4, 2579-2584.

23. Zhumekenov, A. A.; Haque, M. A.; Yin, J.; El-Zohry, A. M.; Lee, K. J.; Dursun, I.; Mohammed, O. F.; Baran, D.; Bakr, O. M. Reduced ion migration and enhanced photoresponse in cuboid crystals of methylammonium lead iodide perovskite. J. Phys. D: Appl. Phys. 2019, 52, 054001. 
24. Wei, H.; Fang, Y.; Mulligan, P.; Chuirazzi, W.; Fang, H.-H.; Wang, C.; Ecker, B. R.; Gao, Y.; Loi, M. A.; Cao, L.; et al. Sensitive X-ray detectors made of methylammonium lead tribromide perovskite single crystals. Nat. Photonics. 2016, 10, 333-339.

25. Shrestha, S.; Fischer, R.; Matt, G. J.; Feldner, P.; Michel, T.; Osvet, A.; Levchuk, I.; Merle, B.; Golkar, S.; Chen, H.; et al. High-performance direct conversion X-ray detectors based on sintered hybrid lead triiodide perovskite wafers. Nat. Photonics. 2017, 11, 436-440.

26. Wei, W.; Zhang, Y.; Xu, Q.; Wei, H.; Fang, Y.; Wang, Q.; Deng, Y.; Li, T.; Gruverman, A.; Cao, L.; et al. Monolithic integration of hybrid perovskite single crystals with heterogenous substrate for highly sensitive X-ray imaging. Nat. Photonics. 2017, 11, 315-321.

27. Zhuang, R.; Wang, X.; Ma, W.; Wu, Y.; Chen, X.; Tang, L.; Zhu, H.; Liu, J.; Wu, L.; Zhou, W.; et al. Highly sensitive X-ray detector made of layered perovskite-like $\left(\mathrm{NH}_{4}\right)_{3} \mathrm{Bi}_{2} \mathrm{I}_{9}$ single crystal with anisotropic response. Nat. Photonics. 2019, 13, 602-608. 28. Chen, Q.; Wu, J.; Ou, X.; Huang, B.; Almutlaq, J.; Zhumekenov, A. A.; Guan, X.; Han, S.; Liang, L.; Yi, Z.; et al. All-inorganic perovskite nanocrystal scintillators. Nature 2018, 561, 88-93.

29. Zhang, Y.; Sun, R.; Ou, X.; Fu, K.; Chen, Q.; Ding, Y.; Xu, L. J.; Liu, L.; Han, Y.; Malko, A. V.; et al. Metal Halide Perovskite Nanosheet for X-ray High-Resolution Scintillation Imaging Screens. ACS Nano 2019, 13, 2520-2525.

30. Yakunin, S.; Protesescu, L.; Krieg, F.; Bodnarchuk, M. I.; Nedelcu, G.; Humer, M.; De Luca, G.; Fiebig, M.; Heiss, W.; Kovalenko, M. V. Low-threshold amplified spontaneous emission and lasing from colloidal nanocrystals of caesium lead halide perovskites. Nat. Commun. 2015, 6, 8056 .

31. Zhu, H.; Fu, Y.; Meng, F.; Wu, X.; Gong, Z.; Ding, Q.; Gustafsson, M. V.; Trinh, M. T.; Jin, S.; Zhu, X. Y. Lead halide perovskite nanowire lasers with low lasing thresholds and high quality factors. Nat. Mater. 2015, 14, 636-642.

32. Wang, K.; Sun, W.; Li, J.; Gu, Z.; Xiao, S.; Song, Q. Unidirectional Lasing Emissions from $\mathrm{CH}_{3} \mathrm{NH}_{3} \mathrm{PbBr}_{3}$ Perovskite Microdisks. Acs Photonics. 2016, 3, 1125 1130. 
33. Zhang, Q.; Su, R.; Liu, X.; Xing, J.; Sum, T. C.; Xiong, Q. High-Quality Whispering-Gallery-Mode Lasing from Cesium Lead Halide Perovskite Nanoplatelets. Adv. Funct. Mater. 2016, 26, 6238-6245.

34. Wang, K.; Wang, S.; Xiao, S.; Song, Q. Recent Advances in Perovskite Micro- and Nanolasers. Adv. Opt. Mater. 2018, 6, 1800278.

35. Hassan, Y.; Ashton, O. J.; Park, J. H.; Li, G.; Sakai, N.; Wenger, B.; Haghighirad, A.-A.; Noel, N. K.; Song, M. H.; Lee, B. R.; et al. Facile Synthesis of Stable and Highly Luminescent Methylammonium Lead Halide Nanocrystals for Efficient Light Emitting Devices. J. Am. Chem. Soc. 2019, 141, 1269-1279.

36. Lin, K.; Xing, J.; Quan, L. N.; de Arquer, F. P. G.; Gong, X.; Lu, J.; Xie, L.; Zhao, W.; Zhang, D.; Yan, C.; et al. Perovskite light-emitting diodes with external quantum efficiency exceeding 20 percent. Nature. 2018, 562, 245-248.

37. Yuan, Z.; Zhou, C.; Tian, Y.; Shu, Y.; Messier, J.; Wang, J. C.; van de Burgt, L. J.; Kountouriotis, K.; Xin, Y.; Holt, E.; et al. One-dimensional organic lead halide perovskites with efficient bluish white-light emission. Nat. Commun. 2017, 8, 14051. 38. Lanzetta, L.; Marin-Beloqui, J. M.; Sanchez-Molina, I.; Ding, D.; Haque, S. A. Two-Dimensional Organic Tin Halide Perovskites with Tunable Visible Emission and Their Use in Light-Emitting Devices. ACS Energy Lett. 2017, 2, 1662-1668.

39. Dang, Y.; Liu, Y.; Sun, Y.; Yuan, D.; Liu, X.; Lu, W.; Liu, G.; Xia, H.; Tao, X. Bulk crystal growth of hybrid perovskite material $\mathrm{CH}_{3} \mathrm{NH}_{3} \mathrm{PbI}_{3}$. CrystEngComm. 2015, 17, 665-670.

40. Liu, Y.; Yang, Z.; Cui, D.; Ren, X.; Sun, J.; Liu, X.; Zhang, J.; Wei, Q.; Fan, H.; Yu, F.; et al. Two-Inch-Sized Perovskite $\mathrm{CH}_{3} \mathrm{NH}_{3} \mathrm{PbX}_{3}(\mathrm{X}=\mathrm{Cl}, \mathrm{Br}$, I) Crystals: Growth and Characterization. Adv. Mater. 2015, 27, 5176-5183.

41. Saidaminov, M. I.; Abdelhady, A. L.; Murali, B.; Alarousu, E.; Burlakov, V. M.; Peng, W.; Dursun, I.; Wang, L.; He, Y.; Maculan, G.; et al. High-quality bulk hybrid perovskite single crystals within minutes by inverse temperature crystallization. Nat. Commun. 2015, 6, 7586.

42. Zhumekenov, A. A.; Saidaminov, M. I.; Haque, M. A.; Alarousu, E.; Sarmah, S. P.; Murali, B.; Dursun, I.; Miao, X.-H.; Abdelhady, A. L.; Wu, T.; et al. Formamidinium 
Lead Halide Perovskite Crystals with Unprecedented Long Carrier Dynamics and Diffusion Length. ACS Energy Lett. 2016, 1, 32-37.

43. Saidaminov, M. I.; Abdelhady, A. L.; Maculan, G.; Bakr, O. M. Retrograde solubility of formamidinium and methylammonium lead halide perovskites enabling rapid single crystal growth. Chem. Commun. 2015, 51, 17658-17661.

44. Cho, N.; Li, F.; Turedi, B.; Sinatra, L.; Sarmah, S. P.; Parida, M. R.; Saidaminov, M. I.; Murali, B.; Burlakov, V. M.; Goriely, A.; et al. Pure crystal orientation and anisotropic charge transport in large-area hybrid perovskite films. Nat. Commun. 2016, $7,13407$.

45. Murali, B.; Yengel, E.; Yang, C.; Peng, W.; Alarousu, E.; Bakr, O. M.; Mohammed, O. F. The Surface of Hybrid Perovskite Crystals: A Boon or Bane. ACS Energy Lett. 2017, 2, 846-856.

46. Murali, B.; Kolli, H. K.; Yin, J.; Ketavath, R.; Bakr, O. M.; Mohammed, O. F. Single Crystals: The Next Big Wave of Perovskite Optoelectronics. ACS Mater. Lett. 2019, 2 , $184-214$

47. Alarousu, E.; El-Zohry, A. M.; Yin, J.; Zhumekenov, A. A.; Yang, C.; Alhabshi, E.; Gereige, I.; AlSaggaf, A.; Malko, A. V.; Bakr, O. M.; et al. Ultralong Radiative States in Hybrid Perovskite Crystals: Compositions for Submillimeter Diffusion Lengths. $J$. Phys. Chem. Lett. 2017, 8, 4386-4390.

48. Liu, Y.; Zhang, Y.; Zhao, K.; Yang, Z.; Feng, J.; Zhang, X.; Wang, K.; Meng, L.; Ye, H.; Liu, M.; et al. A $1300 \mathrm{~mm}^{2}$ Ultrahigh-Performance Digital Imaging Assembly using High-Quality Perovskite Single Crystals. Adv. Mater. 2018, 30, 1707314.

49. Shi, D.; Adinolfi, V.; Comin, R.; Yuan, M.; Alarousu, E.; Buin, A.; Chen, Y.; Hoogland, S.; Rothenberger, A.; Katsiev, K.; et al. Low trap-state density and long carrier diffusion in organolead trihalide perovskite single crystals. Science 2015, 347, 519-522.

50. Zhumekenov, A. A.; Burlakov, V. M.; Saidaminov, M. I.; Alofi, A.; Hague, M. A.; Turedi, B.; Davaasuren, B.; Dursun, I.; Cho, N.; El-Zohry, A. M.; et al. The Role of Surface Tension in the Crystallization of Metal Halide Perovskites. ACS Energy Lett. 2017, 2, 1782-1788. 
51. Brenner, T. M.; Egger, D. A.; Kronik, L.; Hodes, G.; Cahen, D. Hybrid organicinorganic perovskites: low-cost semiconductors with intriguing charge-transport properties. Nat. Rev. Mater. 2016, 1, 15007.

52. Song, Y.; Bi, W.; Wang, A.; Liu, X.; Kang, Y.; Dong, Q. Efficient lateral-structure perovskite single crystal solar cells with high operational stability. Nat. Commun. 2020, $11,274-274$.

53. Guan, Y.; Xu, M.; Zhang, W.; Li, D.; Hou, X.; Hong, L.; Wang, Q.; Zhang, Z.; Mei, A.; Chen, M.; Zhou, Y.; Padture, N. P.; Hu, Y.; Rong, Y.; Han, H. In situ transfer of $\mathrm{CH} 3 \mathrm{NH} 3 \mathrm{PbI} 3$ single crystals in mesoporous scaffolds for efficient perovskite solar cells. Chem. Sci. 2020, 11, 474-481.

54. Cheng, X.; Yang, S.; Cao, B.; Tao, X.; Chen, Z. Single Crystal Perovskite Solar Cells: Development and Perspectives. Adv. Funct. Mater. 2020, 30, 1905021.

55. Lian, Z.; Yan, Q.; Lv, Q.; Wang, Y.; Liu, L.; Zhang, L.; Pan, S.; Li, Q.; Wang, L.; Sun, J.-L. High-Performance Planar-Type Photodetector on (100) Facet of $\mathrm{MAPbI}_{3}$ Single Crystal. Sci Rep. 2015, 5, 16563.

56. Birowosuto, M. D.; Cortecchia, D.; Drozdowski, W.; Brylew, K.; Lachmanski, W.; Bruno, A.; Soci, C. X-ray Scintillation in Lead Halide Perovskite Crystals. Sci Rep. 2016, 6, 37254 .

57. Yakunin, S.; Dirin, D. N.; Shynkarenko, Y.; Morad, V.; Cherniukh, I.; Nazarenko, O.; Kreil, D.; Nauser, T.; Kovalenko, M. V. Detection of gamma photons using solutiongrown single crystals of hybrid lead halide perovskites. Nat. Photonics. 2016, 10, $585-$ 589.

58. Wang, G.; Li, D.; Cheng, H.-C.; Li, Y.; Chen, C.-Y.; Yin, A.; Zhao, Z.; Lin, Z.; Wu, H.; He, Q.; et al. Wafer-scale growth of large arrays of perovskite microplate crystals for functional electronics and optoelectronics. Sci. Adv. 2015, 1, e1500613.

59. Sichert, J. A.; Tong, Y.; Mutz, N.; Vollmer, M.; Fischer, S.; Milowska, K. Z.; Cortadella, R. G.; Nickel, B.; Cardenas-Daw, C.; Stolarczyk, J. K.; et al. Quantum Size Effect in Organometal Halide Perovskite Nanoplatelets. Nano Lett. 2015, 15, 65216527.

60. Liu, Z.; Mi, Y.; Guan, X.; Su, Z.; Liu, X.; Wu, T. Morphology-Tailored Halide 
Perovskite Platelets and Wires: From Synthesis, Properties to Optoelectronic Devices. Adv. Opt. Mater. 2018, 6, 1800413.

61. Fu, Y.; Zhu, H.; Schrader, A. W.; Liang, D.; Ding, Q.; Joshi, P.; Hwang, L.; Zhu, X. Y.; Jin, S. Nanowire Lasers of Formamidinium Lead Halide Perovskites and Their Stabilized Alloys with Improved Stability. Nano Lett. 2016, 16, 1000-1008.

62. Pan, J.; Li, X.; Gong, X.; Yin, J.; Zhou, D.; Sinatra, L.; Huang, R.; Liu, J.; Chen, J.; Dursun, I.; et al. Halogen Vacancies Enable Ligand-Assisted Self-Assembly of Perovskite Quantum Dots into Nanowires. Angew. Chem. Int. Ed. 2019, 58, 1607716081.

63. Chen, M.; Shan, X.; Geske, T.; Li, J.; Yu, Z. Manipulating Ion Migration for Highly Stable Light-Emitting Diodes with Single-Crystalline Organometal Halide Perovskite Microplatelets. ACS Nano. 2017, 11, 6312-6318.

64. Hu, X.; Zhou, H.; Jiang, Z.; Wang, X.; Yuan, S.; Lan, J.; Fu, Y.; Zhang, X.; Zheng, W.; Wang, X.; et al. Direct Vapor Growth of Perovskite $\mathrm{CsPbBr}_{3}$ Nanoplate Electroluminescence Devices. ACS Nano. 2017, 11, 9869-9876.

65. Zhou, H.; Yuan, S.; Wang, X.; Xu, T.; Wang, X.; Li, H.; Zheng, W.; Fang, P.; Li, Y.; Sun, L.; et al. Vapor Growth and Tunable Lasing of Band Gap Engineered Cesium Lead Halide Perovskite Micro/Nanorods with Triangular Cross Section. ACS Nano. 2017, 11, 1189-1195.

66. Wang, K.; Wang, S.; Xiao, S.; Song, Q. Recent Advances in Perovskite Micro- and Nanolasers. Adv. Opt. Mater. 2018, 6, 1800278.

67. Imran, M.; Caligiuri, V.; Wang, M.; Goldoni, L.; Prato, M.; Krahne, R.; De Trizio, L.; Manna, L. Benzoyl Halides as Alternative Precursors for the Colloidal Synthesis of Lead-Based Halide Perovskite Nanocrystals. J. Am. Chem. Soc. 2018, 140, 2656-2664. 68. Rao, L.; Tang, Y.; Yan, C.; Li, J.; Zhong, G.; Tang, K.; Yu, B.; Li, Z.; Zhang, J. Z. Tuning the emission spectrum of highly stable cesium lead halide perovskite nanocrystals through poly(lactic acid)-assisted anion-exchange reactions. J. Mater. Chem. C. 2018, 6, 5375-5383.

69. Shi, Y.; Duan, P.; Huo, S.; Li, Y.; Liu, M. Endowing Perovskite Nanocrystals with Circularly Polarized Luminescence. Adv. Mater. 2018, 30, 1705011. 
70. Sun, J.; Yang, J.; Lee, J. I.; Cho, J. H.; Kang, M. S. Lead-Free Perovskite Nanocrystals for Light-Emitting Devices. J. Phys. Chem. Lett. 2018, 9, 1573-1583.

71. Ahmed, G. H.; Liu, J.; Parida, M. R.; Murali, B.; Bose, R.; AlYami, N. M.; Hedhili, M. N.; Peng, W.; Pan, J.; Besong, T. M.; et al. Shape-Tunable Charge Carrier Dynamics at the Interfaces between Perovskite Nanocrystals and Molecular Acceptors. J. Phys. Chem. Lett. 2016, 7, 3913-3919.

72. Liu, J.; Song, K.; Shin, Y.; Liu, X.; Chen, J.; Yao, K. X.; Pan, J.; Yang, C.; Yin, J.; $\mathrm{Xu}$, L.-J.; et al. Light-Induced Self-Assembly of Cubic CsPbBr 3 Perovskite Nanocrystals into Nanowires. Chem. Mater. 2019, 31, 6642-6649.

73. Chen, Y.-X.; Ge, Q.-Q.; Shi, Y.; Liu, J.; Xue, D.-J.; Ma, J.-Y.; Ding, J.; Yang, H.-J.; Hu, J.-S.; Wan, L.-J. General Space-Confined On-Substrate Fabrication of ThicknessAdjustable Hybrid Perovskite Single-Crystalline Thin Films. J. Am. Chem. Soc. 2016, $138,16196-16199$.

74. Liu, Y.; Zhang, Y.; Yang, Z.; Yang, D.; Ren, X.; Pang, L.; Liu, S. Thinness- and Shape-Controlled Growth for Ultrathin Single-Crystalline Perovskite Wafers for Mass Production of Superior Photoelectronic Devices. Adv. Mater. 2016, 28, 9204-9209.

75. Deng, W.; Huang, L.; Xu, X.; Zhang, X.; Jin, X.; Lee, S.-T.; Jie, J. UltrahighResponsivity Photodetectors from Perovskite Nanowire Arrays for Sequentially Tunable Spectral Measurement. Nano Lett. 2017, 17, 2482-2489.

76. Fu, Y.; Meng, F.; Rowley, M. B.; Thompson, B. J.; Shearer, M. J.; Ma, D.; Hamers, R. J.; Wright, J. C.; Jin, S. Solution Growth of Single Crystal Methylammonium Lead Halide Perovskite Nanostructures for Optoelectronic and Photovoltaic Applications. $J$. Am. Chem. Soc. 2015, 137, 5810-5818.

77. Nielsen, A. E. Kinetics of Precipitation; Pergamon: Oxford, UK, 1964.

78. Zhang, L.; Liu, Y.; Ye, X.; Han, Q.; Ge, C.; Cui, S.; Guo, Q.; Zheng, X.; Zhai, Z.;

Tao, X. Exploring Anisotropy on Oriented Wafers of MAPbBr 3 Crystal Grown by Controlled Antisolvent Diffusion. Cryst. Growth Des. 2018, 18, 6652-6660.

79. Zhou, Y.; Game, O. S.; Pang, S.; Padture, N. P. Microstructures of Organometal Trihalide Perovskites for Solar Cells: Their Evolution from Solutions and Characterization. J. Phys. Chem. Lett. 2015, 6, 4827-4839. 
80. Jung, M.; Ji, S.-G.; Kim, G.; Seok, S. I. Perovskite precursor solution chemistry: from fundamentals to photovoltaic applications. Chem. Soc. Rev. 2019, 48, 2011-2038. 81. Liu, Y.; Dong, Q.; Fang, Y.; Lin, Y.; Deng, Y.; Huang, J. Fast Growth of Thin $\mathrm{MAPbI}_{3}$ Crystal Wafers on Aqueous Solution Surface for Efficient Lateral-Structure Perovskite Solar Cells. Adv. Funct. Mater. 2019, 29, 1807707.

82. Polavarapu, L.; Mourdikoudis, S.; Pastoriza-Santos, I.; Perez-Juste, J. Nanocrystal engineering of noble metals and metal chalcogenides: controlling the morphology, composition and crystallinity. Crystengcomm. 2015, 17, 3727-3762.

83. Lignos, I.; Stavrakis, S.; Nedelcu, G.; Protesescu, L.; deMello, A. J.; Kovalenko, M. V. Synthesis of Cesium Lead Halide Perovskite Nanocrystals in a Droplet-Based Microfluidic Platform: Fast Parametric Space Mapping. Nano Lett. 2016, 16, 18691877.

84. Saidaminov, M. I.; Adinolfi, V.; Comin, R.; Abdelhady, A. L.; Peng, W.; Dursun, I.; Yuan, M.; Hoogland, S.; Sargent, E. H.; Bakr, O. M. Planar-integrated single-crystalline perovskite photodetectors. Nat. Commun. 2015, 6, 8724 .

85. Adinolfi, V.; Ouellette, O.; Saidaminov, M. I.; Walters, G.; Abdelhady, A. L.; Bakr, O. M.; Sargent, E. H. Fast and Sensitive Solution-Processed Visible-Blind Perovskite UV Photodetectors. Adv. Mater. 2016, 28, 7264-7268.

86. Ahmad, R.; Surendran, A.; Harikesh, P. C.; Haselsberger, R.; Jamaludin, N. F.; John, R. A.; Koh, T. M.; Bruno, A.; Leong, W. L.; Mathews, N.; et al. Perturbation-Induced Seeding and Crystallization of Hybrid Perovskites over Surface-Modified Substrates for Optoelectronic Devices. ACS Appl. Mater. Interfaces. 2019, 11, 27727-27734.

87. Liao, Q.; Hu, K.; Zhang, H.; Wang, X.; Yao, J.; Fu, H. Perovskite Microdisk Microlasers Self-Assembled from Solution. Adv. Mater. 2015, 27, 3405-3410.

88. Arciniegas, M. P.; Castelli, A.; Piazza, S.; Dogan, S.; Ceseracciu, L.; Krahne, R.; Duocastella, M.; Manna, L. Laser-Induced Localized Growth of Methylammonium Lead Halide Perovskite Nano- and Microcrystals on Substrates. Adv. Funct. Mater. 2017, 27, 1701613.

89. Saidaminov, M. I.; Haque, M. A.; Savoie, M.; Abdelhady, A. L.; Cho, N.; Dursun, I.; Buttner, U.; Alarousu, E.; Wu, T.; Bakr, O. M. Perovskite Photodetectors Operating 
in Both Narrowband and Broadband Regimes. Adv. Mater. 2016, 28, 8144-8149.

90. Shamsi, J.; Abdelhady, A. L.; Accornero, S.; Arciniegas, M.; Goldoni, L.; Kandada, A. R. S.; Petrozza, A.; Manna, L. N-Methylformamide as a Source of Methylammonium Ions in the Synthesis of Lead Halide Perovskite Nanocrystals and Bulk Crystals. ACS Energy Lett. 2016, 1, 1042-1048.

91. Yang, B.; Zhang, F.; Chen, J.; Yang, S.; Xia, X.; Pullerits, T.; Deng, W.; Han, K. Ultrasensitive and Fast All-Inorganic Perovskite-Based Photodetector via Fast Carrier Diffusion. Adv. Mater. 2017, 29, 1703758.

92. Zhou, H.; Zeng, J.; Song, Z.; Grice, C. R.; Chen, C.; Song, Z.; Zhao, D.; Wang, H.; Yan, Y. Self-Powered All-Inorganic Perovskite Microcrystal Photodetectors with High Detectivity. J. Phys. Chem. Lett. 2018, 9, 2043-2048.

93. Yang, Z.; Deng, Y.; Zhang, X.; Wang, S.; Chen, H.; Yang, S.; Khurgin, J.; Fang, N. X.; Zhang, X.; Ma, R. High-Performance Single-Crystalline Perovskite Thin-Film Photodetector. Adv. Mater. 2018, 30, 1704333.

94. Ding, R.; Liu, C.-K.; Wu, Z.; Guo, F.; Pang, S.-Y.; Wong, L. W.; Io, W. F.; Yuan, S.; Wong, M.-C.; Jedrzejczyk, M. B.; Zhao, J.; Yan, F.; Hao, J. A General Wet Transferring Approach for Diffusion-Facilitated Space-Confined Grown Perovskite Single-Crystalline Optoelectronic Thin Films. Nano Lett. 2020, 20, 2747-2755.

95. Chen, J.; Morrow, D. J.; Fu, Y.; Zheng, W.; Zhao, Y.; Dang, L.; Stolt, M. J.; Kohler, D. D.; Wang, X.; Czech, K. J.; Hautzinger, M. P.; Shen, S.; Guo, L.; Pan, A.; Wright, J. C.; Jin, S. Single-Crystal Thin Films of Cesium Lead Bromide Perovskite Epitaxially Grown on Metal Oxide Perovskite $\left(\mathrm{SrTiO}_{3}\right)$. J. Am. Chem. Soc. 2017, 139, $13525-$ 13532.

96. Chen, Z.; Turedi, B.; Alsalloum, A. Y.; Yang, C.; Zheng, X.; Gereige, I.; AlSaggaf, A.; $\quad$ Mohammed, O. F.; Bakr, O. M. Single-Crystal $\mathrm{MAPbI}_{3}$ Perovskite Solar Cells Exceeding 21\% Power Conversion Efficiency. ACS Energy Lett. 2019, 4, 1258-1259.

97. Alsalloum, A. Y.; Turedi, B.; Zheng, X.; Mitra, S.; Zhumekenov, A. A.; Lee, K. J.; $\quad$ Maity, P.; Gereige, I.; AlSaggaf, A.; Roqan, I. S.; Mohammed, O. F.; Bakr, O. M. Low-Temperature Crystallization Enables 21.9\% Efficient Single- 
Crystal MAPbI 3 Inverted Perovskite Solar Cells. ACS Energy Lett. 2020, 5, 657-662.

98. Peng, W.; Wang, L.; Murali, B.; Ho, K. T.; Bera, A.; Cho, N.; Kang, C.

F.; Burlakov, V. M.; Pan, J.; Sinatra, L.; Ma, C.; Xu, W.; Shi, D.; Alarousu,

E.; Goriely, A.; He, J. H.; Mohammed, O. F.; Wu, T.; Bakr, O. M. SolutionGrown Monocrystalline Hybrid Perovskite Films for Hole-Transporter-Free Solar Cells. Adv. Mater. 2016, 28, 3383-90.

99. Bao, C.; Chen, Z.; Fang, Y.; Wei, H.; Deng, Y.; Xiao, X.; Li, L.; Huang, J. LowNoise and Large-Linear-Dynamic-Range Photodetectors Based on Hybrid-Perovskite Thin-Single-Crystals. Adv. Mater. 2017, 29, 1703209.

100. Chen, Z.; Li, C.; Zhumekenov, A. A.; Zheng, X.; Yang, C.; Yang, H.; He, Y.; Turedi, B.; Mohammed, O. F.; Shen, L.; et al. Solution-Processed Visible-Blind Ultraviolet Photodetectors with Nanosecond Response Time and High Detectivity. Adv. Opt. Mater. 2019, 7, 1900506.

101. Lee, L.; Baek, J.; Park, K. S.; Lee, Y.-E.; Shrestha, N. K.; Sung, M. M. Wafer-scale single-crystal perovskite patterned thin films based on geometrically-confined lateral crystal growth. Nat. Commun. 2017, 8, 15882.

102 Liu, Y.; Ren, X.; Zhang, J.; Yang, Z.; Yang, D.; Yu, F.; Sun, J.; Zhao, C.; Yao, Z.; Wang, B.; et al. $120 \mathrm{~mm}$ single-crystalline perovskite and wafers: towards viable applications. Sci. China-Chem. 2017, 60, 1367-1376.

103. Liu, Y.; Sun, J.; Yang, Z.; Yang, D.; Ren, X.; Xu, H.; Yang, Z.; Liu, S. 20-mmLarge Single-Crystalline Formamidinium-Perovskite Wafer for Mass Production of Integrated Photodetectors. Adv. Opt. Mater. 2016, 4, 1829-1837.

104. Tong, Y.; Ehrat, F.; Vanderlinden, W.; Cardenas-Daw, C.; Stolarczyk, J. K.; Polavarapu, L.; Urban, A. S. Dilution-Induced Formation of Hybrid Perovskite Nanoplatelets. Acs Nano 2016, 10, 10936-10944.

105. Weidman, M. C.; Seitz, M.; Stranks, S. D.; Tisdale, W. A. Highly Tunable Colloidal Perovskite Nanoplatelets through Variable Cation, Metal, and Halide Composition. Acs Nano 2016, 10, 7830-7839.

106. Li, Y.; Shi, Z.; Lei, L.; Zhang, F.; Ma, Z.; Wu, D.; Xu, T.; Tian, Y.; Zhang, Y.; Du, G.; Shan, C.; Li, X. Highly Stable Perovskite Photodetector Based on Vapor- 
Processed Micrometer-Scale CsPbBr 3 Microplatelets. Chem. Mater. 2018, 30, 67446755.

107. Yang, B.; Chen, J.; Shi, Q.; Wang, Z.; Gerhard, M.; Dobrovolsky, A.; Scheblykin,

I. G.; Karki, K. J.; Han, K.; Pullerits, T. High Resolution Mapping of Two-Photon Excited Photocurrent in Perovskite Microplate Photodetector. J. Phys. Chem. Lett. 2018, 9, 5017-5022.

108. Gui, P.; Zhou, H.; Yao, F.; Song, Z.; Li, B.; Fang, G. Space-Confined Growth of Individual Wide Bandgap Single Crystal $\mathrm{CsPbCl}_{3}$ Microplatelet for Near-Ultraviolet Photodetection. Small 2019, 15, 1902618.

109. Gu, Z.; Zhou, Z.; Huang, Z.; Wang, K.; Cai, Z.; Hu, X.; Li, L.; Li, M.; Zhao, Y. S.; Song, Y. Controllable Growth of High-Quality Inorganic Perovskite Microplate Arrays for Functional Optoelectronics. Adv. Mater. 2020, 32, 1908006.

110. Shamsi, J.; Kubicki, D.; Anaya, M.; Liu, Y.; Ji, K.; Frohna, K.; Grey, C. P.; Friend, R. H.; Stranks, S. D. Stable Hexylphosphonate-Capped Blue-Emitting QuantumConfined CsPbBr3 Nanoplatelets. ACS Energy Lett. 2020, 5, 1900-1907.

111. Uddin, M. A.; Glover, J. D.; Park, S. M.; Pham, J. T.; Graham, K. R. Growth of Highly Stable and Luminescent $\mathrm{CsPbX}_{3}(\mathrm{X}=\mathrm{Cl}, \mathrm{Br}$, and I) Nanoplates via Ligand Mediated Anion Exchange of $\mathrm{CsPbCl} 3$ Nanocubes with A1X3. Chem. Mater. 2020, 32, $5217-5225$.

112. Zhang, Q.; Ha, S. T.; Liu, X.; Sum, T. C.; Xiong, Q. Room-Temperature NearInfrared High-Q Perovskite Whispering-Gallery Planar Nano lasers. Nano Lett. 2014, 14, 5995-6001.

113. Wang, Y.; Shi, Y.; Xin, G.; Lan, J.; Shi, J. Two-Dimensional van der Waals Epitaxy Kinetics in a Three-Dimensional Perovskite Halide. Cryst. Growth Des. 2015, 15, 47414749 .

114. Liang, D.; Peng, Y.; Fu, Y.; Shearer, M. J.; Zhang, J.; Zhai, J.; Zhang, Y.; Hamers, R. J.; Andrew, T. L.; Jin, S. Color-Pure Violet-Light-Emitting Diodes Based on Layered Lead Halide Perovskite Nanoplates. ACS Nano. 2016, 10, 6897-6904.

115. Cai, Z.; Liu, B.; Zou, X.; Cheng, H.-M. Chemical Vapor Deposition Growth and Applications of Two-Dimensional Materials and Their Heterostructures. Chem. Rev. 
2018, 118, 6091-6133.

116. Tyagi, P.; Arveson, S. M.; Tisdale, W. A. Colloidal Organohalide Perovskite Nanoplatelets Exhibiting Quantum Confinement. J. Phys. Chem. Lett. 2015, 6, 19111916.

117. Akkerman, Q. A.; Motti, S. G.; Kandada, A. R. S.; Mosconi, E.; D'Innocenzo, V.; Bertoni, G.; Marras, S.; Kamino, B. A.; Miranda, L.; De Angelis, F.; et al. Solution Synthesis Approach to Colloidal Cesium Lead Halide Perovskite Nanoplatelets with Monolayer-Level Thickness Control. J. Am. Chem. Soc. 2016, 138, 1010-1016.

118. Ling, Y.; Yuan, Z.; Tian, Y.; Wang, X.; Wang, J. C.; Xin, Y.; Hanson, K.; Ma, B.; Gao, H. Bright Light-Emitting Diodes Based on Organometal Halide Perovskite Nanoplatelets. Adv. Mater. 2016, 28, 305-311.

119. Yang, B.; Mao, X.; Yang, S.; Li, Y.; Wang, Y.; Wang, M.; Deng, W.; Han, K. Low Threshold Two-Photon-Pumped Amplified Spontaneous Emission in $\mathrm{CH}_{3} \mathrm{NH}_{3} \mathrm{PbBr}_{3}$ Microdisks. ACS Appl. Mater. Interfaces. 2016, 8, 19587-19592.

120. Jeon, T.; Kim, S. J.; Yoon, J.; Byun, J.; Hong, H. R.; Lee, T.-W.; Kim, J.-S.; Shin, B.; Kim, S. O. Hybrid Perovskites: Effective Crystal Growth for Optoelectronic Applications. Adv. Energy Mater. 2017, 7, 1602596.

121. Liu, J.; Xue, Y.; Wang, Z.; Xu, Z.-Q.; Zheng, C.; Weber, B.; Song, J.; Wang, Y.; Lu, Y.; Zhang, Y.; et al. Two-Dimensional $\mathrm{CH}_{3} \mathrm{NH}_{3} \mathrm{PbI}_{3}$ Perovskite: Synthesis and Optoelectronic Application. Acs Nano. 2016, 10, 3536-3542.

122. Aharon, S.; Etgar, L. Two Dimensional Organometal Halide Perovskite Nanorods with Tunable Optical Properties. Nano Lett. 2016, 16, 3230-3235.

123. Li, Y.; Huang, H.; Xiong, Y.; Richter, A. F.; Kershaw, S. V.; Feldmann, J.; Rogach, A. L. Using Polar Alcohols for the Direct Synthesis of Cesium Lead Halide Perovskite Nanorods with Anisotropic Emission. ACS Nano. 2019, 13, 8237-8245.

124. Talapin, D. V.; Koeppe, R.; Gotzinger, S.; Kornowski, A.; Lupton, J. M.; Rogach, A. L.; Benson, O.; Feldmann, J.; Weller, H. Highly emissive colloidal CdSe/CdS heterostructures of mixed dimensionality. Nano Lett. 2003, 3, 1677-1681.

125. Tong, Y.; Fu, M.; Bladt, E.; Huang, H.; Richter, A. F.; Wang, K.; MuellerBuschbaum, P.; Bals, S.; Tamarat, P.; Lounis, B.; Feldmann, J.; Polavarapu, L. Chemical 
Cutting of Perovskite Nanowires into Single-Photon Emissive Low-Aspect-Ratio $\mathrm{CsPbX}_{3}(\mathrm{X}=\mathrm{Cl}, \mathrm{Br}, \mathrm{I})$ Nanorods. Angew. Chem. Int. Edit. 2018, 57, 16094-16098.

126. Zhang, X.; Bai, X.; Wu, H.; Zhang, X.; Sun, C.; Zhang, Y.; Zhang, W.; Zheng, W.; Yu, W. W.; Rogach, A. L. Water-Assisted Size and Shape Control of $\mathrm{CsPbr}_{3}$ Perovskite Nanocrystals. Angew. Chem. Int. Ed. 2018, 57, 3337-3342.

127. Schmidt, L. C.; Pertegas, A.; Gonzalez-Carrero, S.; Malinkiewicz, O.; Agouram, S.; Minguez Espallargas, G.; Bolink, H. J.; Galian, R. E.; Perez-Prieto, J. Nontemplate Synthesis of $\mathrm{CH}_{3} \mathrm{NH}_{3} \mathrm{PbBr}_{3}$ Perovskite Nanoparticles. J. Am. Chem. Soc. 2014, 136, 850-853.

128. Protesescu, L.; Yakunin, S.; Bodnarchuk, M. I.; Krieg, F.; Caputo, R.; Hendon, C. H.; Yang, R. X.; Walsh, A.; Kovalenko, M. V. Nanocrystals of Cesium Lead Halide Perovskites $\left(\mathrm{CsPbX}_{3}, \mathrm{X}=\mathrm{Cl}, \mathrm{Br}\right.$, and I): Novel Optoelectronic Materials Showing Bright Emission with Wide Color Gamut. Nano Lett. 2015, 15, 3692-3696.

129. Zhang, F.; Zhong, H.; Chen, C.; Wu, X.-g.; Hu, X.; Huang, H.; Han, J.; Zou, B.; Dong, Y. Brightly Luminescent and Color-Tunable Colloidal $\mathrm{CH}_{3} \mathrm{NH}_{3} \mathrm{PbX}_{3}(\mathrm{X}=\mathrm{Br}, \mathrm{I}$, Cl) Quantum Dots: Potential Alternatives for Display Technology. ACS Nano 2015, 9 , $4533-4542$.

130. Steirer, K. X.; Schulz, P.; Teeter, G.; Stevanovic, V.; Yang, M.; Zhu, K.; Berry, J. J. Defect Tolerance in Methylammonium Lead Triiodide Perovskite. ACS Energy Lett. 2016, 1, 360-366.

131. Paul, S.; Samanta, A. N-Bromosuccinimide as Bromide Precursor for Direct Synthesis of Stable and Highly Luminescent Green-Emitting Perovskite Nanocrystals. ACS Energy Lett. 2020, 5, 64-69.

132. Zhang, B.; Goldon, L.; Zito, J.; Dang, Z.; Almeida, G.; Zaccaria, F.; de Wit, J.; Infante, I.; De Trizio, L.; Manna, L. Alkyl Phosphonic Acids Deliver $\mathrm{CsPbBr}_{3}$ Nanocrystals with High Photoluminescence Quantum Yield and Truncated Octahedron Shape. Chem. Mater. 2019, 31, 9140-9147.

133. Chen, M.; Hu, H.; Tan, Y.; Yao, N.; Zhong, Q.; Sun, B.; Cao, M.; Zhang, Q.; Yin, Y. Controlled growth of dodecapod-branched $\mathrm{CsPbBr}_{3}$ nanocrystals and their application in white light emitting diodes. Nano Energy 2018, 53, 559-566. 
134. Zhong, Q.; Cao, M.; Hu, H.; Yang, D.; Chen, M.; Li, P.; Wu, L.; Zhang, Q. OnePot Synthesis of Highly Stable CsPbBr $@ \mathrm{SiO}_{2}$ Core-Shell Nanoparticles. Acs Nano 2018, $12,8579-8587$.

135. Chen, W.; Hao, J.; Hu, W.; Zang, Z.; Tang, X.; Fang, L.; Niu, T.; Zhou, M. Enhanced Stability and Tunable Photoluminescence in Perovskite CsPbX3/ZnS Quantum Dot Heterostructure. Small 2017, 13, 1604085.

136. Li, Z.-J.; Hofman, E.; Li, J.; Davis, A. H.; Tung, C.-H.; Wu, L.-Z.; Zheng, W. Photoelectrochemically Active and Environmentally Stable $\mathrm{CsPbBr} / \mathrm{TiO}_{2}$ Core/Shell Nanocrystals. Adv. Funct. Mater. 2018, 28, 1704288.

137. Zhang, X.; Lu, M.; Zhang, Y.; Wu, H.; Shen, X.; Zhang, W.; Zheng, W.; Colvin, V. L.; Yu, W. W. PbS Capped $\mathrm{CsPbI}_{3}$ Nanocrystals for Efficient and Stable LightEmitting Devices Using p-i-n Structures. ACS Cent. Sci. 2018, 4, 1352-1359.

138. Tang, X.; Yang, J.; Li, S.; Liu, Z.; Hu, Z.; Hao, J.; Du, J.; Leng, Y.; Qin, H.; Lin, X.; et al. Single Halide Perovskite/Semiconductor Core/Shell Quantum Dots with Ultrastability and Nonblinking Properties. Adv. Sci. 2019, 6, 1900412.

139. Sun, S.; Yuan, D.; Xu, Y.; Wang, A.; Deng, Z. Ligand-Mediated Synthesis of Shape-Controlled Cesium Lead Halide Perovskite Nanocrystals via Reprecipitation Process at Room Temperature. Acs Nano. 2016, 10, 3648-3657.

140. Imran, M.; Di Stasio, F.; Dang, Z.; Canale, C.; Khan, A. H.; Shamsi, J.; Brescia, R.; Prato, M.; Manna, L. Colloidal Synthesis of Strongly Fluorescent CsPbBr3 Nanowires with Width Tunable down to the Quantum Confinement Regime. Chem. Mater. 2016, 28, 6450-6454.

141. Zhang, D.; Yang, Y.; Bekenstein, Y.; Yu, Y.; Gibson, N. A.; Wong, A. B.; Eaton, S. W.; Kornienko, N.; Kong, Q.; Lai, M.; Alivisatos, A. P.; Leone, S. R.; Yang, P. Synthesis of Composition Tunable and Highly Luminescent Cesium Lead Halide Nanowires through Anion-Exchange Reactions. J. Am. Chem. Soc. 2016, 138, 7236-7239.

142. Zhang, D.; Yu, Y.; Bekenstein, Y.; Wong, A. B.; Alivisatos, A. P.; Yang, P. Ultrathin Colloidal Cesium Lead Halide Perovskite Nanowires. J. Am. Chem. Soc. 2016, $138,13155-13158$.

143. Imran, M.; Ijaz, P.; Baranov, D.; Goldoni, L.; Petralanda, U.; Akkerman, Q.; 
Abdelhady, A. L.; Prato, M.; Bianchini, P.; Infante, I.; Manna, L. Shape-Pure, Nearly Monodispersed $\mathrm{CsPbBr}_{3}$ Nanocubes Prepared Using Secondary Aliphatic Amines. Nano Lett. 2018, 18, 7822-7831.

144. Tong, Y.; Bohn, B. J.; Bladt, E.; Wang, K.; Mueller-Buschbaum, P.; Bals, S.; Urban, A. S.; Polavarapu, L.; Feldmann, J. From Precursor Powders to CsPbX3 Perovskite Nanowires: One-Pot Synthesis, Growth Mechanism, and Oriented SelfAssembly. Angew. Chem. Int. Edit. 2017, 56, 13887-13892.

145. Zhang, D.; Eaton, S. W.; Yu, Y.; Dou, L.; Yang, P. Solution-Phase Synthesis of Cesium Lead Halide Perovskite Nanowires. J. Am. Chem. Soc. 2015, 137, 9230-9233. 146. Amgar, D.; Stern, A.; Rotem, D.; Porath, D.; Etgar, L. Tunable Length and Optical Properties of $\mathrm{CsPbX}_{3}(\mathrm{X}=\mathrm{Cl}, \mathrm{Br}$, I) Nanowires with a Few Unit Cells. Nano Lett. 2017, 17, 1007-1013.

147. Brenes, R.; Guo, D.; Osherov, A.; Noel, N. K.; Eames, C.; Hutter, E. M.; Pathak, S. K.; Niroui, F.; Friend, R. H.; Islam, M. S.; Snaith, H. J.; Bulovic, V.; Savenije, T. J.; Stranks, S. D. Metal Halide Perovskite Polycrystalline Films Exhibiting Properties of Single Crystals. Joule 2017, 1, 155-167.

148. Wenger, B.; Nayak, P. K.; Wen, X.; Kesava, S. V.; Noel, N. K.; Snaith, H. J. Consolidation of the optoelectronic properties of $\mathrm{CH} 3 \mathrm{NH} 3 \mathrm{PbBr} 3$ perovskite single crystals. Nat. Commun. 2017, 8, 590.

149. Gong, O. Y.; Kim, Y.; Kim, D. H.; Han, G. S.; Jeong, S.; Jung, H. S. Revisiting Effects of Ligand-Capped Nanocrystals in Perovskite Solar Cells. ACS Energy Lett. 2020, 5, 1032-1034.

150. Dou, L.; Wong, A. B.; Yu, Y.; Lai, M.; Kornienko, N.; Eaton, S. W.; Fu, A.;

Bischak, C. G.; Ma, J.; Ding, T.; Ginsberg, N. S.; Wang, L. W.; Alivisatos, A. P.; Yang, P. Atomically thin two-dimensional organic-inorganic hybrid perovskites. Science 2015, 349, 1518-1521. 
ToC

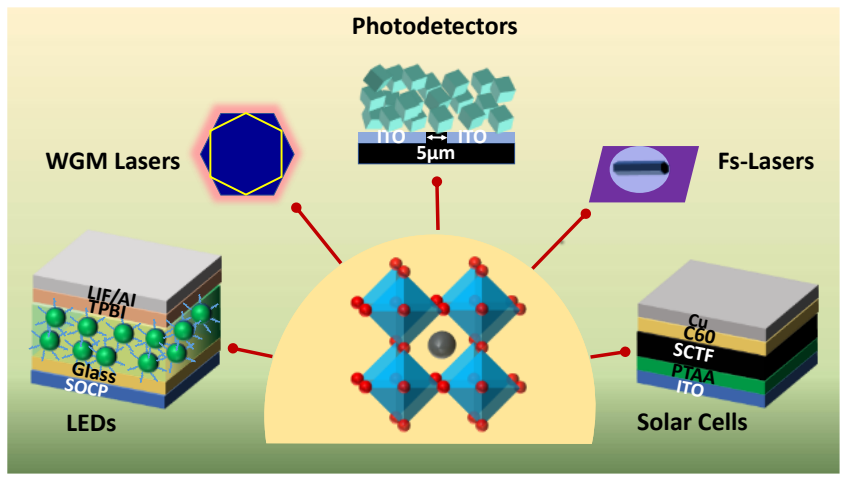

